\title{
Mental fatigue measurement using eye metrics: A systematic literature review
}

\author{
Bafna, Tanya; Hansen, John Paulin
}

Published in:

Psychophysiology

Link to article, DOI:

$10.1111 /$ psyp. 13828

Publication date:

2021

Document Version

Publisher's PDF, also known as Version of record

Link back to DTU Orbit

Citation (APA):

Bafna, T., \& Hansen, J. P. (2021). Mental fatigue measurement using eye metrics: A systematic literature review. Psychophysiology, 58(6), [e13828]. https://doi.org/10.1111/psyp.13828

\section{General rights}

Copyright and moral rights for the publications made accessible in the public portal are retained by the authors and/or other copyright owners and it is a condition of accessing publications that users recognise and abide by the legal requirements associated with these rights.

- Users may download and print one copy of any publication from the public portal for the purpose of private study or research.

- You may not further distribute the material or use it for any profit-making activity or commercial gain

- You may freely distribute the URL identifying the publication in the public portal

If you believe that this document breaches copyright please contact us providing details, and we will remove access to the work immediately and investigate your claim 


\title{
Mental fatigue measurement using eye metrics: A systematic literature review
}

\author{
Tanya Bafna (iD) | John Paulin Hansen (1)
}

Department of Technology, Management and Economics, Technical University of Denmark, Kongens Lyngby, Denmark

\section{Correspondence}

Tanya Bafna, Department of Technology, Management and Economics, Akademivej 358, 2800 Kongens Lyngby, Denmark.

Email: taba@dtu.dk

\section{Funding information}

This work was partially funded by the Bevica Foundation and the Horizon 2020 Framework Program of the European Union under the ReHyb Project, Grant Agreement Number 871767

\begin{abstract}
Mental fatigue measurement techniques utilize one or a combination of the cognitive, affective, and behavioral responses of the body. Eye-tracking and electrooculography, which are used to compute eye-based features, have gained momentum with increases in accuracy and robustness of the lightweight equipment emerging in the markets and can be used for objective and continuous assessment of mental fatigue. The main goal of this systematic review was to summarize the various eye-based features that have been used to measure mental fatigue and explore the relation of eye-based features to mental fatigue. The review process, following the preferred reporting items for systematic reviews and meta-analyses, used the electronic databases Web of Science, Scopus, ACM digital library, IEEE Xplore, and PubMed. Of the 1,385 retrieved documents, 34 studies met the inclusion criteria, resulting in 21 useful eye-based features. Categorizing these into eight groups revealed saccades as the most promising category, with saccade mean and peak velocity providing quick access to the cognitive states within 30 min of fatiguing activity. Complex brain networks involving sympathetic and parasympathetic nervous systems control the relation of mental fatigue to tonic pupil size and have the potential to indicate mental fatigue in controlled experimental conditions. Other categories, like blinks, are derived from the field of sleep research and should be used with caution. Several limitations emerged in the analysis, including varied experimental methods, use of dim lighting during the experiment (that could possibly also induce sleepiness), and use of unclear data analysis techniques, thereby complicating comparisons between studies.
\end{abstract}

\section{K E Y W OR D S}

electrooculography, eye metrics, eye movements, eye-tracking, mental fatigue, pupillometry

\section{INTRODUCTION}

Mental fatigue affects people in professions like transportation (Itoh et al., 2000; LeDuc et al., 2005; Wise et al., 2019), construction ( $\mathrm{Li}$, Li et al., 2019), and health care (Nielsen et al., 2019; Schlosser et al., 2012), that often include long hours in demanding environments and where it is critical to be vigilant to avoid accidents and injury. Even in the absence of injury prone situations, fatigue affects the productivity and mental health of the workers, resulting in a lower quality of life (Ricci et al., 2007). Furthermore, mental fatigue impacts people with hearing impairment (Wang et al., 2017) or diagnosed with multiple sclerosis (Bryant et al., 2004; Finke et al., 2012; Mills \& Young, 2008; Niepel et al., 2013), amyotrophic lateral sclerosis (Gibbons et al., 2013), or traumatic brain injury (Johansson et al., 2010). It is one of the 
most common complaints made by patients, and it has a severe impact on communication and everyday life (Bryant et al., 2004). Reliable measurement of fatigue under these circumstances is the first step to obtaining a deeper understanding of ways to reduce, manage, and counter this complaint.

Gaze-tracking equipment has become robust, inexpensive and accurate, and gaze sensors may soon be included in computers, phones, tablets, and head-mounted displays (Barz et al., 2018; Hu \& Lodewijks, 2020). The use of eyebased physiological signals derived from blinks (Martins \& Carvalho, 2015; Stern et al., 1984), eye movements (Cazzoli et al., 2014; Hirvonen et al., 2010), and pupils (Marandi et al., 2019; Morad et al., 2000), recorded using eye-tracking (Hopstaken et al., 2015b; Itoh et al., 2000; Li, Chen et al., 2019; Li, Li et al., 2019; Maffei \& Angrilli, 2018; Marandi et al., 2018) and electro-oculography (EOGHirvonen et al., 2010; Tag et al., 2019), have received increased scrutiny in the past years as a means of measuring fatigue (Dawson et al., 2014; Eckstein et al., 2017; Kramer, 1991; Martins \& Carvalho, 2015). Several authors have reviewed fatigue measurement (Aaronson et al., 1999; Hu \& Lodewijks, 2020; Martins \& Carvalho, 2015; Monteiro et al., 2019; Tran et al., 2020); nevertheless, a review summarizing mental fatigue measurement techniques using eye-based technologies is still lacking. The goal of this systematic review is to present an overview of mental fatigue measurement using eyebased features derived from physiological signals.

\section{1 | Defining mental fatigue}

Fatigue is the effect of exertion caused by physical and/or cognitive activity, and the impact on an individual depends on factors like pain, sleep deprivation, circadian rhythm, diet, fitness level, and environment (Phillips, 2015). Numerous classifications have been developed to facilitate a better understanding of fatigue (Finsterer \& Mahjoub, 2014). Fatigue is classified based on its association with an underlying condition into pathological and physiological fatigue. Pathological fatigue that occurs in some medical disorders, such as multiple sclerosis, depression, and rheumatism, is not easily predictable and may be chronic (Chaudhuri \& Behan, 2004; Kluger et al., 2013). In contrast, physiological fatigue is independent of the diagnosis of a medical condition; it is a transient phenomenon caused by sustained exertion and is attenuated by rest (Kluger et al., 2013).

Mental fatigue, a type of physiological fatigue and the focus of this literature review, occurs as a consequence of cognitive processing on a task for a period of time that results in a reduction in cognitive capacity and motivation to continue with the task; it is sometimes accompanied by deteriorated task performance (Boksem \& Tops, 2008; Hopstaken et al., ,2015, 2015a; Pattyn et al., 2018; Tanaka et al., 2014).
Mental fatigue of a transient nature has been termed acute mental fatigue in the literature (van der Linden, 2011). Cognitive load caused by the task and the time spent on the task modulate the degree of the acute mental fatigue experienced during and after the task (Borragán et al., 2017). Motivation and the expected cost and benefits of performing a task determine the amount of effort individuals exert on the task to achieve success (Richter et al., 2016), and thereby modulate the degree of mental fatigue. In this review, fatigue and mental fatigue are used interchangeably and denote acute mental fatigue.

Another concept associated with fatigue and important to define is fatigability. Some authors have defined fatigability as the objective measurement of reduced performance caused by fatigue; and in this case, fatigue is characterized solely as a subjective feeling (Finsterer \& Mahjoub, 2014; Linnhoff et al., 2019). We derive our definition from physiology and sports science research, where muscle fatigability is described as the failure to maintain force during a sustained contraction (Chaudhuri \& Behan, 2004; Zijdewind et al., 2016). Fatigability indicates how fast a specific level of fatigue is achieved and is especially relevant for understanding fatigue in persons with neurological disorders and concussions, who often experience pathological fatigue independent of performing a task. We define mental fatigability as the inability to maintain processing during a sustained cognitive task. People with lower mental fatigability have the capacity to do more before reaching the same fatigue level compared with people with higher fatigability (Eldadah, 2010).

Despite a general agreement in these definitions, fatigue and mental fatigue are often confused with other similar concepts like sleepiness, drowsiness, daytime sleepiness, and weakness (Ream \& Richardson, 1996). Patients and clinicians alike are unable to deconstruct fatigue from the closely associated experience of sleepiness and often combine both feelings under the umbrella term of "tiredness" (Shen et al., 2006). Researchers also tend to use fatigue and sleepiness interchangeably (May \& Baldwin, 2009; Morad et al., 2000) or use sleep deprivation to induce and measure fatigue (Morad et al., 2000; Shen et al., 2008). This lack of differentiation in the papers has been recognized as an important issue in research (Neu et al., 2010), as have attempted to differentiate between the related concepts $(\mathrm{Hu} \&$ Lodewijks, 2020). Sleepiness has been defined as the propensity to sleep, whereas the solution for fatigue is rest but not necessarily sleep (Mairesse et al., 2017). Both sleepiness and fatigue are associated with a reduction in arousal levels (Pattyn et al., 2018).

While the distinction between sleepiness and fatigue is an important one to identify, so is the difference between boredom and fatigue. Low demand in cognitive resources, as a result of monotonous vigilance tasks and boredom, result in an underload condition, whereas a higher than manageable 
demand in cognitive resources leads to a condition of overload, or mental fatigue (Pattyn et al., 2008).

\section{2 | Measurement of mental fatigue}

Two characteristics of fatigue are important considerations for its measurement: (a) fatigue is a subjective phenomenon and (b) fatigue is associated with cognitive, behavioral, and affective responses of the body (Ream \& Richardson, 1996). Measurement of mental fatigue can be summarized in four categories: (1) subjective questionnaires, which often include aspects of affective reaction to fatigue (Piper et al., 1998), (2) attention tests, denoting cognitive response to fatigue, (3) reduced task performance, depicting the behavioral response to fatigue and (4) physiological measurements, such as heart rate, brain activity, and pupil size.

Mental fatigue has been assessed in clinics using numerous questionnaires, like the Fatigue Impact Scale (Fisk et al., 1994), Chalder Fatigue Scale (Chalder et al., 1993), Multidimensional Fatigue Inventory (Smets et al., 1995), and Checklist Individual Strength (Beurskens et al., 2000). These questionnaires assess factors like physical fatigue, mental fatigue, motivation based on a range of 11 to 40 questions (Whitehead, 2009). Using these can result in bias due to subjective reporting (Chaudhuri $\&$ Behan, 2004; Monteiro et al., 2019), and the subjective reports do not always correlate with known objective measures of fatigue (Bailey et al., 2007).

The second method of fatigue measurement is analyses of performance on attention tasks, like the Psychomotor Vigilance Task (Dinges \& Kribbs, 1991), Eriksen Flanker Task (Eriksen \& Eriksen, 1974), and Attention Network Task (Fan et al., 2002). These tasks show effects of fatigue via reduction in performance accuracy and reaction to stimuli. Inevitably, these tasks require a break from the ongoing task and performing an additional, non-familiar task.

The third method associated with mental fatigue and its measurement is the measurement of the behavioral response to fatigue. Reduced performance on an ongoing task, such as reduced accuracy on a working memory task, can depict fatigue. While definitions often align fatigue with reductions in performance, what is often not mentioned in these definitions is that, prior to the performance level decrease, there may be an attempt to maintain the performance by expending more effort. At that stage, therefore, although the person experiences fatigue, there is no reduction in performance (Meijman, 1997).

The use of the fourth method of physiological signals and gaze behavior for mental fatigue measurement has increased in frequency, with the increasingly mobile and accurate technologies of electroencephalography (EEGGergelyfi et al., 2015; Guo et al., 2018; Hopstaken et al., ,2015, 2015a, 2016; Sengupta et al., 2017; Wang et al., 2019), electrocardiography (ECG; Abbasi et al., 2018; Horiuchi et al., 2018), EOG and eye-tracking. Continuous fatigue measurement using these technologies provides data that is unhampered by subjective bias and does not require taking a break from an ongoing task. Among these, eye-tracking and EOG are the technologies that do not rely on time-consuming setup and have minimal contact with the skin (Hu \& Lodewijks, 2020). The recent improvements in terms of accuracy, size of equipment and ease of use for eye-tracking and EOG systems developed in the last years have transpired in the form of ordinary eyeglasses. ${ }^{1,2}$ Although the use of eye-tracking and EOG in the measurement of mental fatigue has increased, no summary of the various eye-based features has been presented that can be reliably used to navigate the measurement of mental fatigue.

\subsection{Objectives and research questions}

The main goal of this systematic review is to determine eyebased features, as derived from psycho-physiological signals and gaze behavior, which are useful for mental fatigue measurement. The research questions are outlined as follows: (1) Which eye-based features have been used in the literature to measure mental fatigue? (2) How do the eye-based features relate to mental fatigue? To answer these questions, we have conducted a systematic review of studies that have measured mental fatigue using eye-based features.

The results of the eye-based metrics used to measure mental fatigue will be provided in a qualitative manner (increase or decrease with increasing mental fatigue), rather than in a quantitative manner (effect size or correlation), due to the variation in the eye-based metrics and units used, as well as the variation in the methods used to induce and record gaze data.

\section{$2 \mid$ METHOD}

We conducted and reported this review as per the guidelines by the Preferred Reporting Items for Systematic reviews and Meta-Analyses statement (PRISMA; Moher et al., 2009). The review protocol was registered in the Open Science Foundation (Bafna \& Hansen, 2020).

\section{1 | Inclusion and exclusion criteria}

We included papers that met the following criteria: (1) a study involving mental fatigue and using a task where the

\footnotetext{
${ }^{1}$ https://jins-meme.com/en/

${ }^{2}$ https://www.tobiipro.com/product-listing/tobii-pro-glasses-3/
} 
fatigue could be subjectively measured, and/or assumed to have incidence after a prolonged time-on-task; (2) eyebased features computed and analyzed for effects of mental fatigue.

We excluded original papers using the following conditions: (1) no English version of the full paper was available; (2) record was not peer-reviewed; (3) fatigue was not mentioned, induced or measured in the experiment described in the paper; (4) the study was performed with non-human participants; (5) the experimental protocol depicted measurements of stress, cognitive load, eye/visual fatigue, drowsiness, or sleepiness, although the title or keywords mentioned fatigue.

\subsection{Search strategy}

We searched five databases-Scopus, Web of Knowledge, ACM Digital Library, PubMed, and IEEE Xplore-for articles published from 1900 to December 2019. Based on keywords found related to the original terms, we modified the search terms used to search in the title, abstract or keywords of the databases. The search string was constructed to include papers measuring mental fatigue using eye-based measures. The detailed search strategy is provided in online Appendix A1. Search terms used to denote fatigue were "fatigue," "tiredness," "fatigability," or "tired," which were used in conjunction with "mental or mentally" or "cognitive or cognitively." Use of eye-based features was denoted by incorporating the terms "pupil," "pupillometry," "eye or eyes," "gaze," or "pupillography," and measurement of fatigue was indicated by including the wildcard version of the terms detect, model, analyze and measure. Subsequently, the main author (TB) conducted the cited reference search.

\section{3 | Study selection}

After the removal of duplicates and papers in a language other than English, we examined the retrieved studies in two phases. In the screening phase, the main author (TB) excluded studies based on the title and the abstract, using the exclusion criteria of measuring stress, cognitive load, mental workload, eye fatigue, visual fatigue, drowsiness, and sleepiness. The next phase was the inclusion phase, where both authors read the full text of the articles to exclude papers that did not follow the inclusion-exclusion criteria. Each author selected the papers independently, and any discrepancies were sorted by mutual agreement. In a final stage, the main author (TB) performed backward reference search from the papers selected for the final inclusion, based on title and abstract, and added them to the screening phase.

\section{4 | Data extraction}

The main author (TB) examined and extracted the following data into a pre-defined database: (a) reference of the paper indicating the first author and the year of publication, (b) the fatiguing task, (c) time spent on the task, (d) number of participants and distribution of sex and age characteristics, (e) eye-based criteria used, their definitions and outcome of the analyses, (f) lighting conditions of the experiment and ( $g$ ) other methods used to assess fatigue. We added the lighting condition in the database following its mention in multiple papers.

\section{5 | Quality assessment}

The papers studied in this review do not fall under the category of randomized controlled trials, so they have no known quality assessment criteria. We created our own criteria, based on previous literature reviews on mental fatigue (Tran et al., 2020) and on factors that were deemed important by us in a paper measuring fatigue using eye-based features. The use of eye-based features is not yet standardized, as in the case of well-established methods like EEG (Tran et al., 2020). Hence, we monitored the definitions and signal processing techniques used in the computation of the eye-based features to evaluate the feasibility of re-using the features and reproducing the experiment. For each category of features, we have listed in online AppendixA2 the sub-criteria used to verify the signal processing techniques used, such as the specification of the stable luminance level for pupil size-based metrics. Partial points were given if some of the sub-criteria were fulfilled. To avoid confounding mental fatigue caused by the task with drowsiness arising from inadequate sleep or varied time used for the experiment, we evaluated the quality of the study based on the instructions given to the participants regarding sleep and the use of a standard time of day in the experimental design. The use of substances like alcohol or coffee has been known to affect fatigue, so we investigated the studies and their instructions to participants regarding this variable, based on the quality assessment criteria in previous literature reviews on mental fatigue (Tran et al., 2020). We gave partial points if one of the substances was included as a restriction in the instructions. Finally, we also evaluated if mental fatigue had been confirmed by another method, such as attention test, questionnaires or technologies such as EEG or ECG. The complete criteria, with their weights, are catalogued in Table 1. 
TABLE 1 Quality assessment criteria

\begin{tabular}{|c|c|c|}
\hline Number & $\begin{array}{l}\text { Quality assessment } \\
\text { question }\end{array}$ & Weight assigned \\
\hline QA1 & $\begin{array}{l}\text { Are the eye-based features } \\
\text { and the signal processing } \\
\text { techniques to compute the } \\
\text { eye-based features clearly } \\
\text { defined? }\end{array}$ & $\begin{array}{l}\text { Yes: } 2 \\
\text { No: } 0\end{array}$ \\
\hline QA2 & $\begin{array}{l}\text { Is the confounding effect of } \\
\text { circadian rhythm addressed } \\
\text { in the experiment design? }\end{array}$ & $\begin{array}{l}\text { Yes: } 1 \\
\text { Not mentioned: } 0\end{array}$ \\
\hline QA3 & $\begin{array}{l}\text { Is the confounding factor of } \\
\text { substance use addressed } \\
\text { during the experiment or } \\
\text { data analysis? }\end{array}$ & $\begin{array}{l}\text { Yes: } 1 \\
\text { No: } 0\end{array}$ \\
\hline QA4 & $\begin{array}{l}\text { Is the confounding effect } \\
\text { of sleep addressed in the } \\
\text { experiment design? }\end{array}$ & $\begin{array}{l}\text { Yes: } 1 \\
\text { No: } 0\end{array}$ \\
\hline QA5 & $\begin{array}{l}\text { What is the number of } \\
\text { participants in the study? }\end{array}$ & $\begin{array}{l}\geq 20 \text { participants } \\
\text { or power analysis } \\
\text { performed: } 2 \\
\text { 10-19 participants: } \\
1.5 \\
6-9 \text { participants: } 1 \\
\text { 1-5 participants: } 0.5 \\
\text { Not specified: } 0\end{array}$ \\
\hline QA6 & $\begin{array}{l}\text { Has mental fatigue been } \\
\text { confirmed using attention } \\
\text { tests, questionnaires or } \\
\text { technology such as EEG, } \\
\text { ECG? }\end{array}$ & $\begin{array}{l}\text { Yes: } 1 \\
\text { No: } 0\end{array}$ \\
\hline
\end{tabular}

\section{3 | RESULTS}

The results obtained from the studies included in the review are structured as follows; Section 3.1 summarizes the study selection process. Sections 3.2 and 3.3 provide the experimental context to the results on the eye-based features and provide an overview of the methods used to induce fatigue and to record fatigue, respectively. They also present a perspective on the variety of methods used, in both inducing fatigue and measuring it. Section 3.4 describes the main results on the various eye-based features, including machine learning results. Lastly, section 3.5 provides the quality assessment results from the studies.

\section{1 $\quad$ Study selection}

A total of 1,384 papers were identified from all the sources-Web Of Science (359), Scopus (796), ACM
Digital Library (20), IEEE Xplore (54), and PubMed (155). An additional paper was found in the personal records of the main author (TB). From these, 895 records were included, after the duplicates and papers not written in English were removed. These 895 records were screened by reading their title and abstract, if they measured mental fatigue and were peer-reviewed, which resulted in 125 papers to be read completely. Based on the inclusion criteria, 32 papers were identified and included in this review. These 32 papers cited 60 relevant papers, as per their title and abstract, which were added to the screening step. Papers that were read completely from these were 18 in number, and two were selected for the final inclusion list, resulting in 34 papers. The process of selection is depicted in Figure 1. These 34 papers had alert participants at the beginning of the study, who reached a state of fatigue at the end of a fatiguing task. Studies that induced fatigue using circadian rhythm were excluded from the review. However, one of the included studies employed both time-on-task and circadian rhythm to induce fatigue and attempted to dissociate both conditions (Cazzoli et al., 2014). Table 2 provides details on the study characteristics and the fatigue-inducing methods (columns 2, 3, and 6) and measurement techniques (column 7).

\section{2 $\quad$ Mental fatigue inducing methods}

Various tasks were used to induce fatigue during the experiment. The tasks associated with each study are provided in column 2 of Table 2, and are depicted in Figure 2.

The experiment duration used in the studies followed a range from 20 min (Maffei \& Angrilli, 2018; Tian et al., 2012) to $18 \mathrm{hr}$ (Di Stasi et al., 2013), and the details are provided in column 3 of Table 2 . The distribution of the studies and the total experimental duration is shown in Figure 3. The experiments were generally divided into trials, where tasks were continuously performed without a break. The trial time of the experiment is given in brackets in column 3 of Table 2, if it differed from the experiment time. Each type of fatiguing task was performed for a broad range of experiment duration, except in the case of driving tasks, which were all performed for $2-3 \mathrm{hr}$.

Twenty-three of the 34 papers reported on the lighting conditions, as controlled in the experimental protocols, and are depicted in column 6 of Table 2. However, 17 of these studies used words like "dim" and "dark" to describe the lighting conditions. We found this detail interesting in the context of fatigue measurement, since fatigue is closely associated with sleepiness, and dim lighting is generally used in sleep measurement protocols (Wei et al., 2019). 


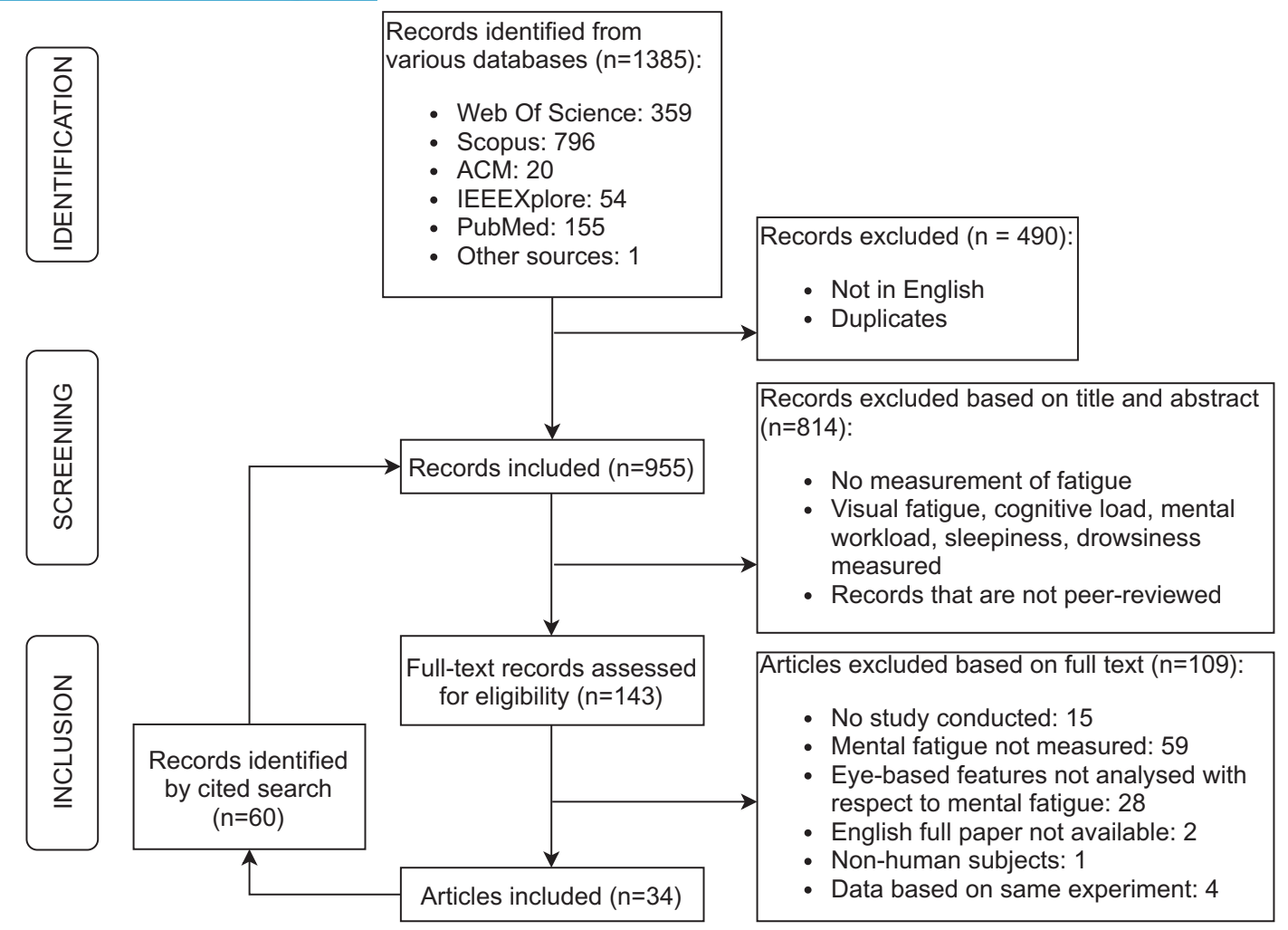

F I G URE 1 Review procedure following the PRISMA strategy

\section{3 | Mental fatigue recording methods}

In 29 of the 34 papers, a fatigue questionnaire was used to confirm that the task applied in the experiment resulted in a change in the subjective feeling of fatigue. The fatigue questionnaires used are provided in column 7 in Table 2. Two studies used known sleepiness questionnaires ( $\mathrm{Li}, \mathrm{Li}$ et al., 2019; Marandi et al., 2018) instead of a fatigue questionnaire, and one of these studies used a workload questionnaire (NASA-TLX) additionally (Li, Li et al., 2019). The rest of the studies (7) assumed that time-on-task would generate fatigue and did not confirm the presence of fatigue at the end of the experiment (Cazzoli et al., 2014; Di Stasi et al., 2015, 2016; Gao et al., 2015; Maffei \& Angrilli, 2018; Tian et al., 2012).

The objective method of fatigue confirmation via attention tasks was performed in only three studies (Gao et al., 2015; Li, Chen et al., 2019; Renata et al., 2018) of the 34 included in the review, and two of these also performed the gaze recording during the attention task ( $\mathrm{Li}, \mathrm{Li}$ et al., 2019; Renata et al., 2018).

In most studies, the physiological measurement of fatigue using eye-based features took place simultaneously as the fatiguing task. In 10 studies, however, an additional gaze-recording task was administered before and after the fatiguing task, with the sole purpose of measuring fatigue by recording the physiological signals. The gaze-recording task is given in column 2 of Table 2, in brackets, with the fatiguing task. The fatiguing tasks that were accompanied by these fatigue measurement tasks were largely real-life fatiguing tasks involving professionals in surgery (Di Stasi, McCamy, Macknik, et al., 2013), aircraft flying (Di Stasi et al., 2016; Diaz-Piedra et al., 2016; LeDuc et al., 2005), and traffic control operation (Li, Li et al., 2019). Di Stasi et al. (2012) conducted gaze-recordings during the fatiguing task of driving as well as during a guided saccade task before and after the driving task.

Nine of the studies conducted multi-modal measurement of fatigue using EEG (Gergelyfi et al., 2015; Guo et al., 2018; Hopstaken et al., ,2015, 2015a, 2016; Sengupta et al., 2017; Wang et al., 2019), ECG (Abbasi et al., 2018; Horiuchi et al., 2018), and functional near-infrared spectroscopy (fNIRS; Borragán et al., 2018) and were able to confirm the corresponding measurements of mental fatigue using eyebased metrics.

\section{4 | Eye-based features}

The eye-based features are categorized into the following eye-metric categories: pupil, percentage of eye closure, blinks, saccades, fixations, microsaccades, ocular drift, and eye activity. Table 3 portrays 21 of the features deemed useful as per the quality assessment criteria and so does not 


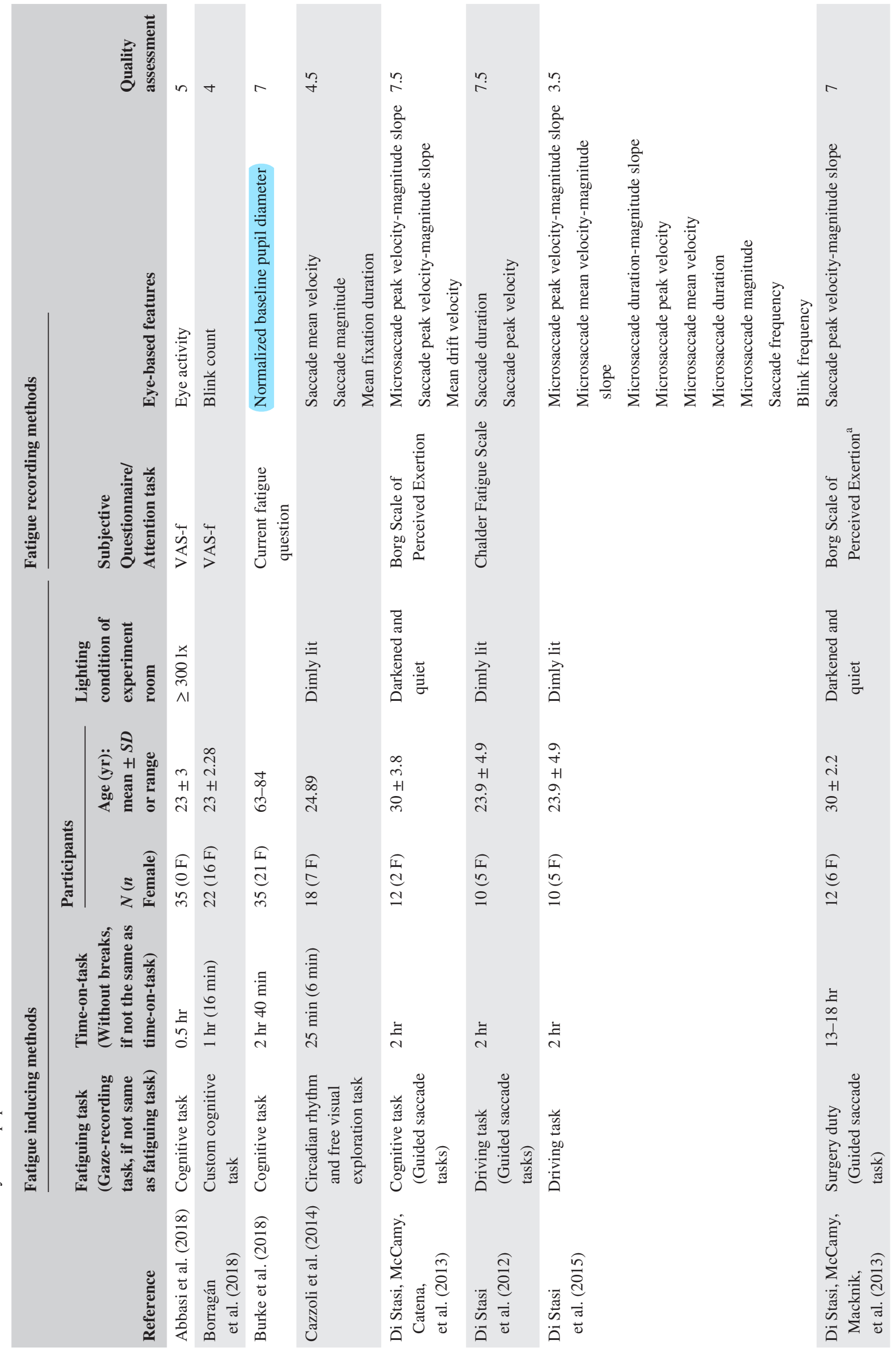




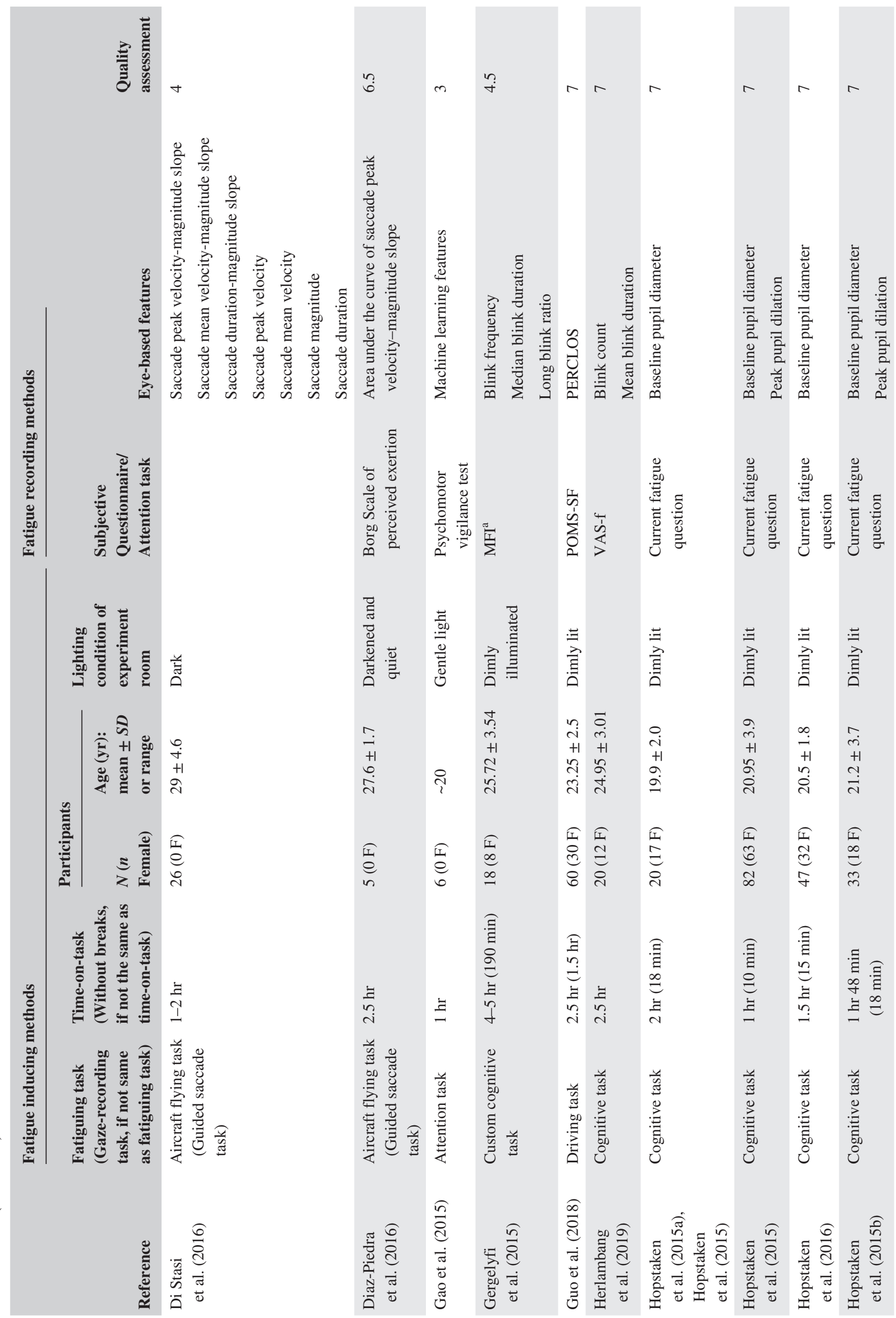




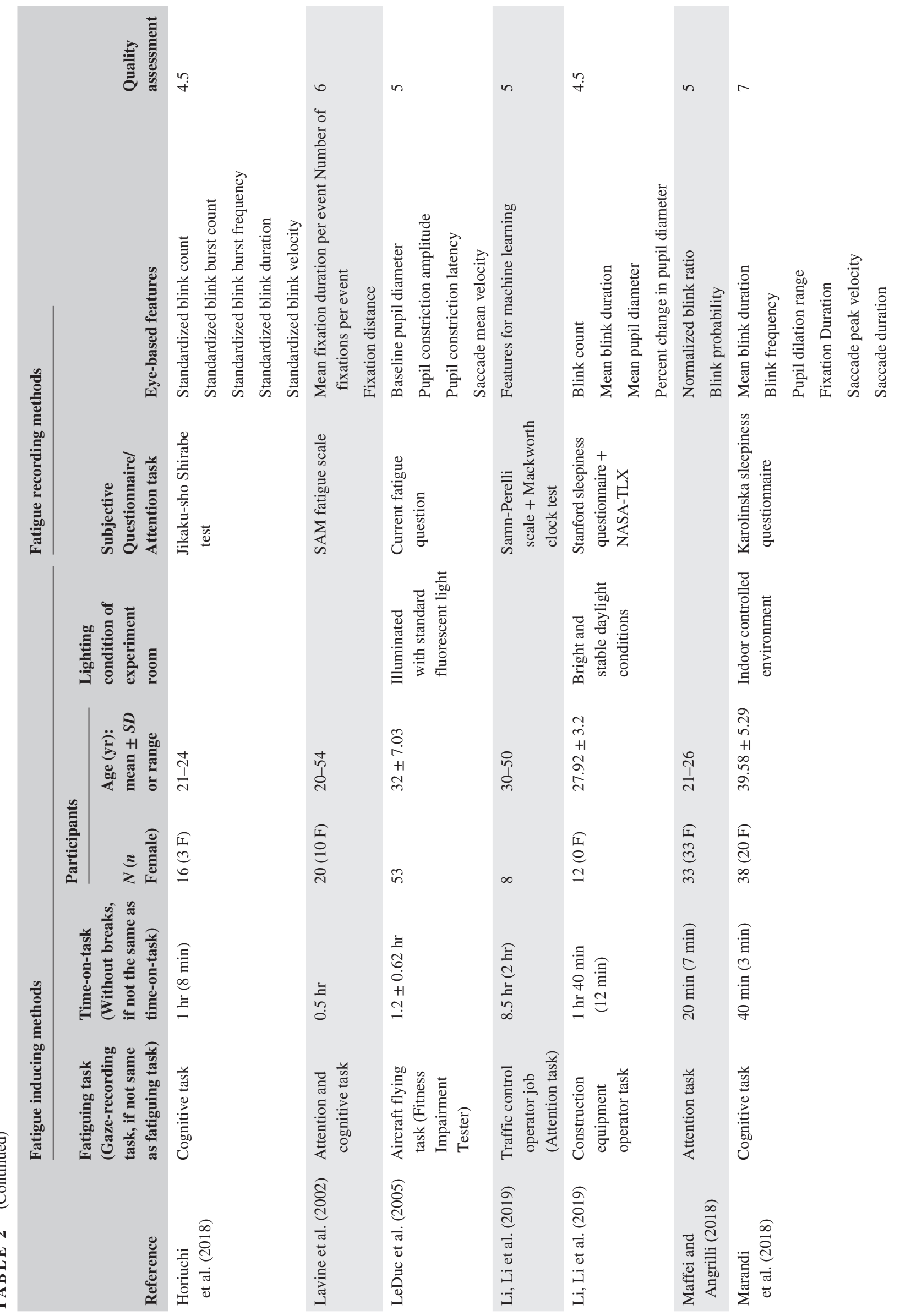




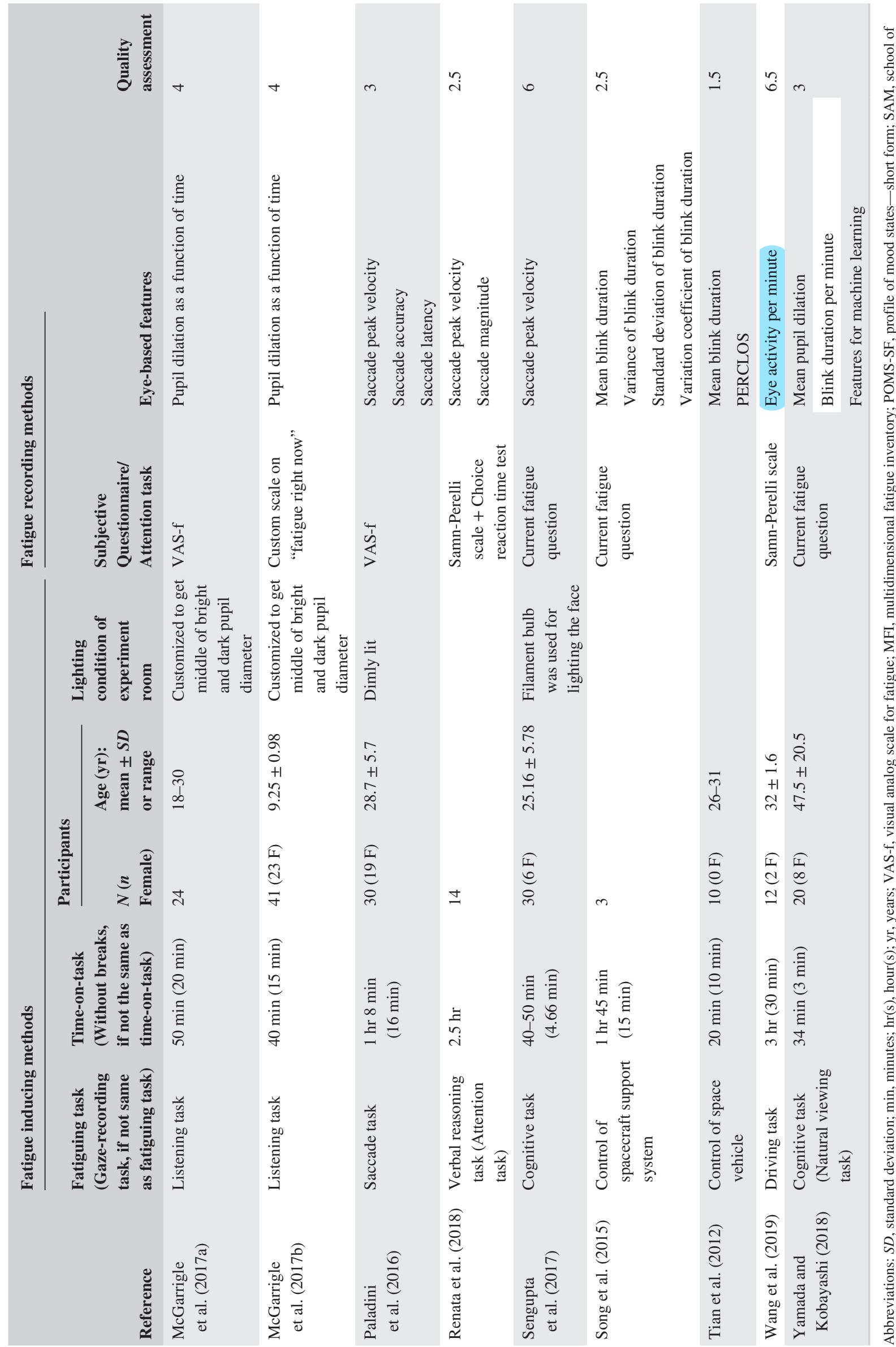

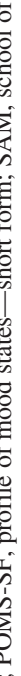




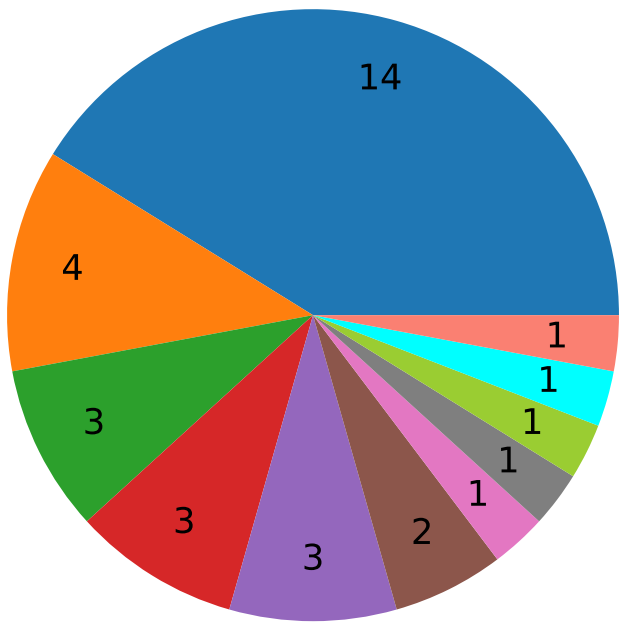

\begin{tabular}{|l|}
\hline Neuro-cognitive task \\
Simulated driving \\
Aircraft flying \\
Noise \\
Attention task \\
Space vehicle control \\
Traffic control shift \\
Health-care shift \\
Simulated construction \\
Saccade task \\
Visual exploration
\end{tabular}

F I G URE 2 Fatigue-inducing tasks used by the included studies

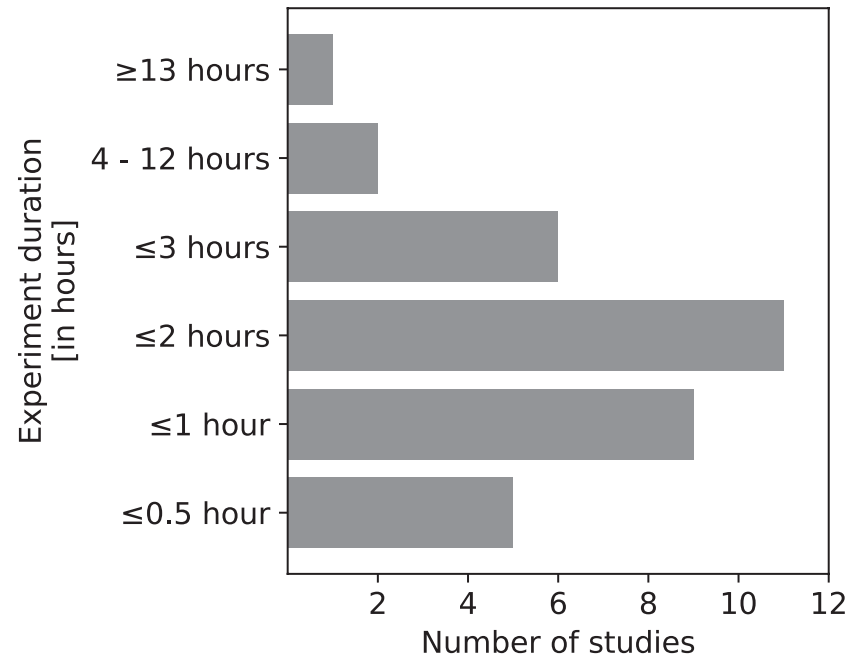

F I G URE 3 Experiment duration of the included studies

include features introduced and used only by papers that have a quality assessment score less than 5 . The table also does not cover the papers that used machine learning algorithms (Gao et al., 2015; Li, Chen et al., 2019; Yamada \& Kobayashi, 2018), as the relation between individual features and mental fatigue was not shown. Additionally, the operational definitions of the features and their relation to mental fatigue, as observed in the included studies, are provided. For a full list of the 52 features covered in all the studies, refer to online Appendix A4.

\subsection{1 | Pupil}

Phasic changes in pupil diameter have been used in various ways to depict mental fatigue. The following pupil-based features reduced as a function of mental fatigue: mean pupil dilation, peak pupil dilation, pupil dilation range (Hopstaken et al., 2015b; Hopstaken et al., 2015; Marandi et al., 2018;
Yamada \& Kobayashi, 2018). The tasks used to induce as well as measure fatigue were cognitive tasks performed for $30 \mathrm{~min}$ to $1.5 \mathrm{hr}$, except for Yamada and Kobayashi (2018), who used a natural viewing task to measure fatigue. Mean pupil diameter, also depicting phasic variations, decreased with time-on-task on a construction equipment operator task of $\sim 2 \mathrm{hr}$ ( $\mathrm{Li}$, Li et al., 2019).

Tonic changes in pupil diameter were obtained using baseline pupil diameter, computed for a short duration before a trial, and were shown to reduce with time-on-task for four of the six studies that used this metric. The four studies showing a decrease in pupil diameter used cognitive tasks for a duration of 1-2.5 hr to induce fatigue (Burke et al., 2018; Hopstaken et al., 2016; Hopstaken et al., 2015a; Hopstaken, et al., 2015). The fifth study that used the baseline pupil diameter also employed a cognitive task of $\sim 2 \mathrm{hr}$, but failed to show a pattern in the data (Hopstaken et al., 2015b). The remaining study compared pupil size before and after an aircraft flying task, and showed an increase in the baseline pupil diameter after the $\sim 1$-hr task (LeDuc et al., 2005).

A pupil-based metric defined by the light conditions- the pupil response to light, was shown to decrease in size and become increasingly delayed under the effect of fatigue caused by $\sim 1 \mathrm{hr}$ of aircraft flying task (LeDuc et al., 2005).

\subsection{2 | Blink}

Three metrics from the blink category were positively correlated with mental fatigue: the blink count, the blink frequency, and the normalized blink ratio, in all the eight studies that measured these. The fatigue inducing as well as measuring task in these studies was mainly a cognitive task (Borragán et al., 2018; Gergelyfi et al., 2015; Herlambang et al., 2019; Horiuchi et al., 2018; Maffei \& Angrilli, 2018; Marandi et al., 2018). One study used a driving task 
TA B LE 3 Eye metrics used to measure mental fatigue, their definitions, and their relation with mental fatigue. $\uparrow$ indicates an increase in the metric with increasing mental fatigue, $\downarrow$ indicates a decrease in the metric with increasing mental fatigue

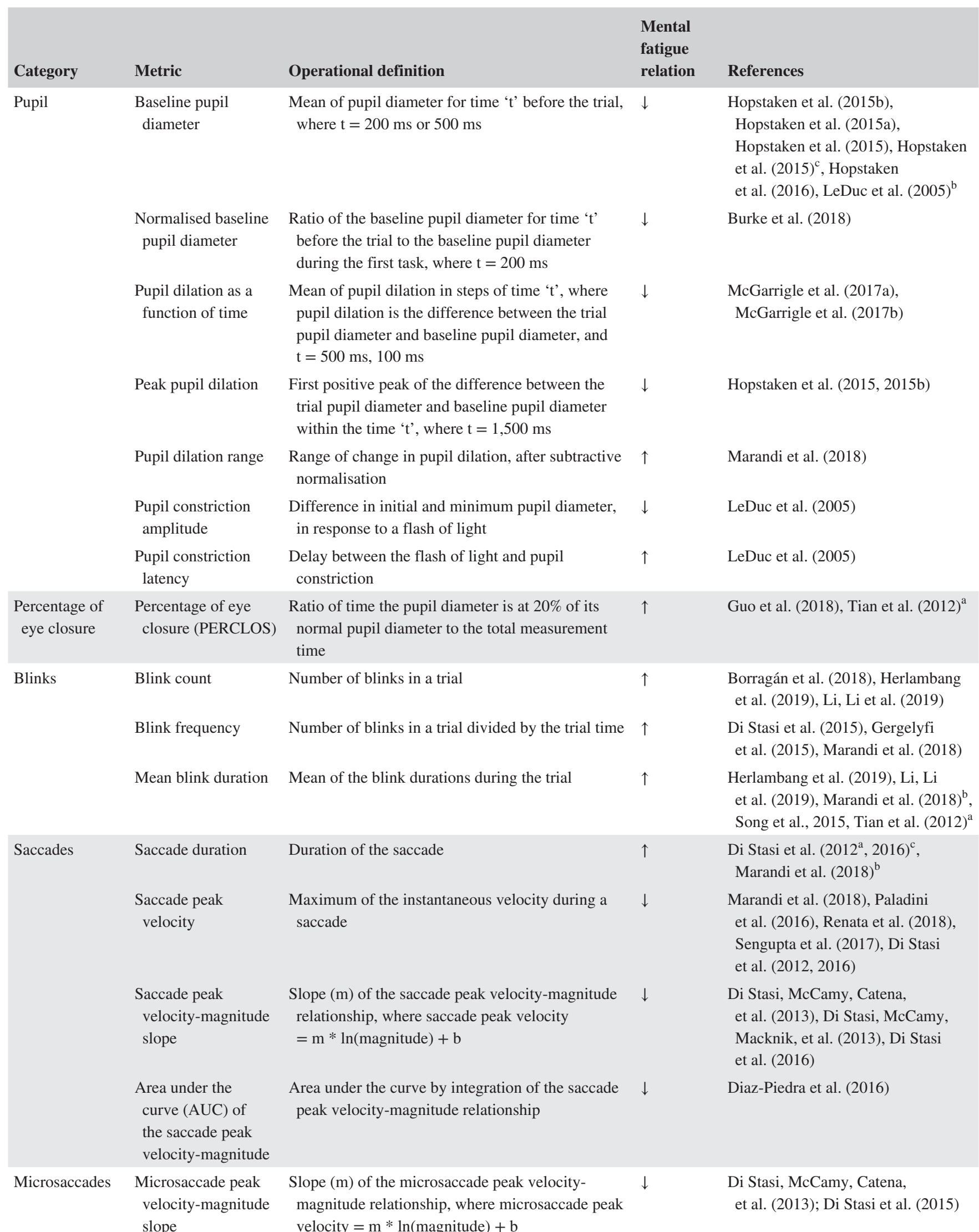


TABLE 3 (Continued)

\begin{tabular}{|c|c|c|c|c|}
\hline Category & Metric & Operational definition & $\begin{array}{l}\text { Mental } \\
\text { fatigue } \\
\text { relation }\end{array}$ & References \\
\hline Eye activity & $\begin{array}{l}\text { EEG-derived eye } \\
\text { activity per minute }\end{array}$ & Number of eye movements per minute & $\downarrow$ & Wang et al. (2019) \\
\hline \multirow{2}{*}{ Fixation } & $\begin{array}{l}\text { Mean fixation } \\
\text { duration }\end{array}$ & Mean of the fixation durations & $\downarrow$ & $\begin{array}{l}\text { Cazzoli et al. }(2014)^{\mathrm{c}} \text {; Lavine } \\
\text { et al. }(2002) \text {; Marandi et al. }(2018)^{\mathrm{c}}\end{array}$ \\
\hline & Fixation distance & $\begin{array}{l}\text { Mean of the distance from fixations to the } \\
\text { geometric center of the target }\end{array}$ & $\uparrow$ & Lavine et al. (2002) \\
\hline
\end{tabular}

${ }^{a}$ The metric was not significant for the reference.; ${ }^{\mathrm{b}}$ The reference showed the opposite relation between the metric and mental fatigue.; ${ }^{\mathrm{c}}$ The reference could not show a notable pattern between the metric and mental fatigue.

(Di Stasi et al., 2015) and another one used a simulated construction work ( $\mathrm{Li}, \mathrm{Li}$ et al., 2019). The task durations varied from $25 \mathrm{~min}$ to $4-5 \mathrm{hr}$.

Mean blink duration was tested by five studies (Herlambang et al., 2019; Li, Li et al., 2019; Marandi et al., 2018; Song et al., 2015; Tian et al., 2012), with mixed results. One study showed a decrease in mean blink duration with increasing mental fatigue on a task of duration $\sim 2 \mathrm{hr}$ (Song et al., 2015), while another reported no significant results on a 20-min fatiguing task (Tian et al., 2012). Both of these studies induced and measured fatigue using a task of controlling space vehicles, as compared to the tasks used by studies that resulted in a positive correlationcognitive tasks and a simulated construction task, all of which had a duration of $40 \mathrm{~min}$ to $2.5 \mathrm{hr}$.

PERCLOS, another derivative of blink duration, also had inconsistent results across the two studies that computed it (Guo et al., 2018; Tian et al., 2012).

\subsection{3 | Saccade and microsaccade}

Two metrics from the category of saccade-peak velocity and mean velocity - were inversely proportional to mental fatigue according to each of the eight studies that used them. Seven of the eight studies generated voluntary saccades using fatiguing tasks such as free visual exploration task (Cazzoli et al., 2014), driving (Di Stasi et al., 2012), aircraft flying (Di Stasi et al., 2016; LeDuc et al., 2005), cognitive tasks (Marandi et al., 2018; Renata et al., 2018; Sengupta et al., 2017). The remaining study involved pro-saccades, a type of saccade generated by following a visual cue, in a gap-overlap saccade task (Paladini et al., 2016). In four of the eight studies, additional fatigue measurement tasks such as a guided saccade task, generating pro-saccades (Di Stasi et al., 2012, 2016; LeDuc et al., 2005) and an attention task, generating voluntary saccades (Renata et al., 2018) were performed before and after the fatiguing task. The duration of these tasks ranged from $25 \mathrm{~min}$ to $2.5 \mathrm{hr}$.

Di Stasi, McCamy, Catena, et al. (2013) tested features of saccades and microsaccades that are a combination of the known existing features. They hypothesized that the main sequence slope (the slope relationship between the saccade/microsaccade magnitude, duration, and velocity) would be affected by cognitive processes such as mental fatigue. They computed the slopes of the main sequences and found that the saccade velocity-magnitude slopes reduced with increasing mental fatigue. The fatiguing tasks in the four studies that used these metrics were all differentaircraft flying (Di Stasi et al., 2016), health-care shift (Di Stasi, McCamy, Macknik, et al., 2013), driving (Di Stasi et al., 2015), and cognitive tasks (Di Stasi, McCamy, Catena, et al., 2013). Three of the four studies used an additional guided saccade task before and after the fatiguing tasks, in order to measure the mental fatigue using prosaccades (Di Stasi, McCamy, Catena, et al., 2013; Di Stasi, McCamy, Macknik, et al., 2013; Di Stasi et al., 2016). All except one study controlled the experiment duration to $2 \mathrm{hr}$; the exception used an experiment duration of 13-18 hr, to generate a health-care shift. In one study, saccade latency, or the reaction time of saccade generation in response to a visual cue, was used to measure the effect of fatigue on attentional disengagement on a gap-overlap task, and found that the saccade latency to shift attention from one visual cue to another (or the cost to disengage) increased with increasing fatigue (Paladini et al., 2016). 


\subsection{4 | Machine learning features and methods}

The features described in Table 3 were analyzed using methods from descriptive statistics. Three papers, however, presented results from inferential statistical methods, so the interpretation of the contribution of individual features to the results is not easy. Gao et al. (2015) used the features blink duration, closing time of the eye, reopening time, blink duration, blink intervals, the velocity of eye closure, the velocity of eye reopening, the energy of blinks, slow eye movement duration and proportions, number of rapid eye movements (REM), and the duration and energy of REMs and used support vector machines (SVM) for fatigue classification. Li, Chen et al. (2019) combined the features gaze velocity probability and entropy to classify fatigue. The data were divided into two states-"fatigue," and "alert," and the researchers used bagged trees to classify fatigue. Yamada and Kobayashi (2018) computed 181 features from four categories-oculomotor (saccades, fixations, blinks, and pupil size), saliency-based features, eye movement directions, and gaze allocation (based on probability and entropy of gaze bins) - to achieve binary classification using a radial basis function kernel SVM.

\section{5 | Quality assessment}

Total scores for the quality assessment criteria are given in column 9 of Table 2, and the individual criterion scores are detailed in online Appendix A3. From a total score of 8, the studies that obtained a score of 5 or above $(>60 \%)$ were considered acceptable in terms of scientific quality. Only 19 of the 34 studies obtained a score of 5 or above, and three studies obtained the highest score of 7.5 (Di Stasi, McCamy, Catena, et al., 2013; Di Stasi et al., 2012; Wang et al., 2019). Twenty studies obtained a full score on the quality assessment criterion 1 and provided an explicit definition of the metrics and the signal processing techniques used on the metric.

We used quality assessment criteria to identify studies that removed the possible causes of sleepiness-a good night's sleep (QA4) and circadian rhythm (QA2), and another criterion to confirm mental fatigue (QA6), to identify the features that were more sensitive to mental fatigue than sleepiness. Five studies fulfilled all three criteria (Burke et al., 2018; Di Stasi, McCamy, Catena, et al., 2013; Di Stasi, McCamy, Macknik, et al., 2013; Di Stasi et al., 2012; Wang et al., 2019). These five studies had used seven different features-normalized baseline pupil diameter, saccade peak velocity-magnitude slope, microsaccade peak velocitymagnitude slope, saccade duration, saccade peak velocity, mean ocular drift velocity, and EEG-derived eye activity per minute - to measure mental fatigue.

\section{4 | DISCUSSION}

This systematic review reports on the eye metrics associated with mental fatigue and describes the relation of the metrics to mental fatigue. Among the 34 studies included in the review, 21 useful eye-based metrics were used to measure mental fatigue, which was induced using a variety of tasks, including cognitive, driving, and attention tasks, for a duration of $20 \mathrm{~min}$ to $18 \mathrm{hr}$. It is crucial, at this stage of research, to provide an overview of the literature and to understand the direction in which the mental fatigue measurement research is headed.

\section{1 | Relation between mental fatigue and eye metrics}

The most promising metrics for fatigue detection were based on saccadic movements. Bahill and Stark (1975) and Schmidt et al. (1979) were the first researchers to study the effects of fatigue on saccade characteristics. Saccade duration was found to increase, while saccade magnitude and velocity reduced for fatigued participant (each study had one fatigued participant). Moreover, Bahill and Stark (1975) claimed that the saccadic points during a fatigued state do not belong to the main sequence (using data from one fatigued participant). Conversely, Di Stasi et al. (2012) plotted the saccade peak velocity versus saccade magnitude data from fatigued participants and the plot follows the expected main sequence curve, but with a different slope. They hypothesized that the slope of the saccadic, as well as microsaccadic main sequence, reduced as a result of fatigue. The slope was found to be significantly reduced due to the effect of mental fatigue, and at the same time, the individual saccade characteristicssaccade magnitude and peak velocity—reduced as an effect of mental fatigue. Although this has not been discussed in the papers, a possible explanation could be that the decrease in saccade peak velocity was higher than the decrease in saccade magnitude, resulting in an overall decrease in their slope. Another observation that supports this theory is that the slope of saccade duration and magnitude is not found to show a notable effect of mental fatigue. Saccade duration and magnitude are known to increase and decrease with time, respectively, and a simultaneous constant change in the slope would mathematically not be possible. Deeper inspection of the reason behind the simultaneous reduction of the saccade velocity-magnitude slope and the individual features with time is required.

Saccade generation is controlled by a structure in the midbrain called superior colliculus (SC). SC is involved in the computation of eye displacement to reach the target and the saccadic velocity (Purves et al., 2001). Another region associated with saccade generation is the brainstem, specifically 
the omnipause neurons. The inhibitory activity of omnipause neurons coincides with the occurrence of saccades, and they have been recently theorized to increase the sensitivity of the saccade-generating neurons-excitatory burst neurons- to the stimuli from SC (Optican, 2008). This increased sensitivity is also responsible for the switch from fixation to saccadic movement. Lesions in omnipause neurons have been linked to a subsequent increase in saccade duration and reduction in saccade velocity (Miura \& Optican, 2006), similar to the effects of fatigue. However, the neural mechanisms preceding these effects of fatigue on saccades are not yet completely understood and need further research.

Pupil size and electrophysiology have previously been exploited using adaptive gain theory, which has been developed in neuroscience to explain the activity of locus coeruleus (LC) neurons and their relation to task engagement and arousal (Aston-Jones \& Cohen, 2005). LC neurons have two modes of activity: phasic and tonic. During the phasic mode, norepinephrine is released in bursts which can be observed as an increase in pupil dilation locked to the task (or stimulusevoked pupil dilation), while the ongoing task is exploited and task performance is improved. During the tonic mode, only baseline norepinephrine is released, and the phasic LC responses are reduced, leading to an exploration of tasks that best utilize the resources and subsequently task performance declines. Based on this theory, Hopstaken et al. (2015b) have proposed a third mode of working of the LC neurons-the disengagement mode. In this mode, both the stimulus-evoked pupil dilation and the baseline pupil diameter decrease in amplitude, and this is accompanied by disengagement from the current task and low attention levels. Using well-designed experiments and cognitive tasks, the baseline pupil diameter (pupil diameter before the task stimulus appeared) was shown to decrease with time-on-task in three out of the five papers that studied it (). Following the same theory, peak pupil dilation was confirmed to reduce with time-on-task. However, this theory on the third output mode of the LC needs further investigation with respect to the LC activity, cognitive load, and the behavioral outcomes of the task.

Pupil response to light, moreover, exhibits delayed effects and a reduced pupil size due to fatigue. This response is a part of the Fitness Impairment Test (FIT), commercially developed to test the fitness of shift workers (PortmanTiller, 1998). Although the results of the original FIT testing did not show correlations between the pupil constriction amplitude and mental fatigue (Portman-Tiller, 1998), LeDuc et al. (2005) successfully showed the effects of mental fatigue using pupil constriction amplitude and latency.

The studies using blinks to indicate fatigue depicted an increase in blink frequency and mean blink duration with timeon-task. John A. Stern et al. (1984) attributed a reduction of blink frequency during a task (visual as well as non-visual) to increased attention to the task, followed by a compensation by an increase in the number of blinks on the completion of the task. Eckstein et al. (2017) have theorized that this reduction in blink frequency during the task leads to the lack of moisture in the eyes and the subsequent increase in blinks toward the end of long experiments.

Neurologically, blink frequency has been used as a noninvasive measure of the neurotransmitter-dopamine due to the robust correlation between the two (Eckstein et al., 2017; Jongkees \& Colzato, 2016; Nieoullon, 2002). This relationship also explains the lower blink frequency in Parkinson's patients, in whom the dopaminergic neurons are degenerating (Lou, 2009). Dopamine is involved in a network of the selfregulation of cognition (Lou, 2009), in the decision-making process of the exploitation of the ongoing task versus the exploration of different tasks (Boksem \& Tops, 2008). When the network in the brain determines that the rewards from the ongoing task do not fulfill the expectations from the task, dopamine level reduces, resulting in the perception of fatigue. This reduction in dopamine is associated with a reduction in blink frequency. This suggests that the explanation of mental fatigue via neuroscience would indicate a decrease in blink frequency. The combined effects of the reduced dopamine, eye moisture, and the compensation for blink suppression, could affect blink measures due to mental fatigue. The increased blink frequency observed in the studies in this review could be due to an overall increase in blink frequency to compensate for blink suppression during the task and to regulate eye moisture. The relative changes in blinks due to each of the above factors need to be further researched.

Similar to blink duration, PERCLOS was hypothesized to increase with fatigue, but it is linked to the propensity to close the eyes during a state of drowsiness, as per the development of the metric for the detection of drowsiness during driving (Wierwille et al., 1994).

Some of the metrics used have no basis in prior hypotheses - pupil dilation range, mean ocular drift velocity, and fixation distance. They showed the effects of mental fatigue in one study each. These metrics are indicators of instability in the gaze and pupil, and they depict an increase in the instability due to mental fatigue (Di Stasi, McCamy, Macknik, et al., 2013).

By employing quality assessment scores, we identified features that could be more sensitive to mental fatigue than sleepiness, using criteria to eliminate the causes of sleepiness, such as inadequate sleep the night before the experiment or circadian effects. This set of features was derived from saccades, microsaccades, pupil, and eye movement. Saccade peak velocity seems the most promising among these, as it was consistent and verified by multiple studies. Another promising feature is normalized baseline pupil diameter, depicting the tonic changes in pupil size as a measure of mental fatigue. The only problem with this feature is the requirement of a controlled environment, to prevent changes in the pupil 
due to varying illumination. This problem has been depicted in the studies included, which employed saccade features in varied indoor and outdoor settings, compared to the controlled laboratory settings where pupil size features were used to analyze effects of mental fatigue. Saccade and microsaccade peak velocity-magnitude slopes were introduced as features by Di Stasi, McCamy, Catena, et al. (2013) and shown to measure fatigue using various fatigue-inducing tasks such as cognitive tasks, surgery duty, aircraft flying, and driving. The tasks used to record eye movements, in the three of the four studies above were guided saccade task, generating prosaccades, and a driving task, causing voluntary saccades, in the last one. These features have shown to be responsive to mental fatigue in varied experimental conditions. Saccade duration, moreover, showed inconsistent results across the three studies it was used in, and requires further research. The last one of the features - eye movement-was computed using EEG frontal cortex electrodes (Wang et al., 2019). The study confirmed mental fatigue using questionnaires as well as using the power spectrum from the EEG signals. Further research is needed to resolve this feature in terms of the eyebased signal from the current EEG signal. An important note here is that none of the above features included blinks, which indicates that blinks are less sensitive to mental fatigue than sleepiness.

\section{2 | Definition of mental fatigue}

Although a definition of mental fatigue is not the basis for this review, it is a foundation for the understanding and measurement of mental fatigue. From the 17 papers that provided their understanding of mental fatigue, the following definition emerged as the accumulated one: mental fatigue is a subjective feeling associated with a reduction in mental resources, including attention and information processing abilities, and a reduced motivation that develops with sustained cognitive effort over time and that can impact task performance.

However, some papers either included drowsiness as a symptom of mental fatigue (Paladini et al., 2016), equated mental fatigue with fatigability (Burke et al., 2018), or provided no explicit understanding of mental fatigue (Di Stasi et al., 2015, 2016; Diaz-Piedra et al., 2016; Horiuchi et al., 2018; Lavine et al., 2002; LeDuc et al., 2005; Li, Chen et al., 2019; McGarrigle et al., 2017a, 2017b; Wang et al., 2019).

There are several existing theories on the generation of mental fatigue, as reviewed by (Pattyn et al., 2018). A traditional theory on fatigue describes a fixed pool of resources, depletion of which results in fatigue. However, this resource theory does not include the influence of motivation on fatigue. We shortly describe two theories which we expect to have merit - the motivational control theory of fatigue and the cost-benefit theory. Both explain a series of computations on the cost of pursuing the current action and the benefits of the goals achieved, but while the latter suggests that the realization that the costs (efforts) required by the task are high and the rewards are low results in a reduced motivation on the task and subsequent increase in fatigue, the former theory suggests that repeated computations of costs and benefits and performing a task with low motivation is the cause for fatigue (Boksem \& Tops, 2008; Hockey, 2010). Boksem \& Tops have backed the cost-benefit theory with neuro-biological evidence on the cost-benefit computations.

\section{3 | Behavior and mental fatigue}

Mental fatigue definitions are generally associated with reductions in performance (Herlambang et al., 2019; Hopstaken et al., 2015a, 2016, 2015; Li, Li et al., 2019; Sengupta et al., 2017), as also proven in 10 of the 34 studies. However, in practice, the feeling of fatigue is often caused by an attempt to maintain performance on the task (Burke et al., 2018; Di Stasi et al., 2015; Marandi et al., 2018), which would result in no or minimal variation in the overall performance. Burke et al. (2018) verified this, as the reaction time on the cognitive task increased, but accuracy did not change, which could indicate that the participants, in an attempt to maintain the accuracy, took even more time to complete the task. Another reason for the low variation in performance could be a temporary increase in arousal levels in order to complete a short and simple task (Di Stasi, McCamy, Macknik, et al., 2013; Hopstaken et al., 2015a, 2015). In other studies, performance measures like accuracy were affected more by motivation (Herlambang et al., 2019) or task difficulty (Di Stasi, McCamy, Catena, et al., 2013; McGarrigle et al., 2017a) than by time.

\section{4 | Limitations}

\subsubsection{Experimental methods}

When combining the studies and investigating the relation between mental fatigue and the eye-based metrics, it quickly became clear that a meta-analysis would not be possible due to the diversity in the experimental methods used. Comparison of the same metric between the studies was difficult for a number of reasons, including the duration of the experiment that varied from $20 \mathrm{~min}$ to $18 \mathrm{hr}$ and the use of various combinations of fatigue, stress, or sleepiness questionnaires to detect the subjective feeling of fatigue. While Tian et al. (2012) obtained a positive correlation between the time-on-task and the mean blink duration for a space-vehicle 
control task of 20 min, they concluded that the task did not cause mental fatigue. However, the results could not be verified due to a lack of analysis of a fatigue questionnaire or behavioral measures. In contrast, Song et al. (2015) found a negative correlation between the mean blink duration and the fatigue score, although the fatigue score increased with time on a spacecraft-support control task that lasted for $1 \mathrm{hr}$ $45 \mathrm{~min}$. Another inexplicable result is the lack of a pattern for the baseline pupil diameter in one study (Hopstaken et al., 2015b), although the same cognitive task performed for a similar amount of time $(\sim 2 \mathrm{hr})$ in similar experimental conditions resulted in a decrease in the baseline pupil diameter (Hopstaken et al., 2015a, 2015).

The diversity in the understanding of mental fatigue in the studies is realized by the variety of fatigue questionnaires used to verify the subjective feeling of mental fatigue. Even when multiple studies used the same questionnaire, a visual analog scale, the original scale had 18 items, whereas McGarrigle et al. (2017a) used a subscale with 13 items, and still others used only one item (Abbasi et al., 2018; Borragán et al., 2018; Herlambang et al., 2019; Paladini et al., 2016).

A number of studies used a driving task to induce mental fatigue, and the conditions of the experiment were monotonous and uncomplicated in three of the four studies. In driving research, this fatigue is termed passive task-related fatigue, and it requires minimal cognitive as well as physical activity. This type of fatigue is related to underload conditions, where participants experience fatigue due to boredom and low cognitive activity, as opposed to overload conditions that require high cognitive demand (May \& Baldwin, 2009). It is debatable to compare the mental fatigue caused by driving in monotonous conditions to cognitive tasks that are customised to generate maximal cognitive load that would still allow high performance (Borragán et al., 2018). The fourth study added a secondary attention task to the existing driving task, which increased the complexity of the mental fatigue experiment and would make the task comparable to other cognitive tasks inducing cognitive load. A possible solution to clarify the cause of mental fatigue would be to verify whether the fatiguing task increases the cognitive load for the participants.

The use of nervous system stimulants such as caffeine can have invigorating effects on humans and counter fatigue (Connell et al., 2017), which is why multiple included studies asked participants to refrain from caffeine before performing the fatigue measurement experiments. However, missing even a morning coffee by habitual caffeine drinkers can initiate withdrawal effects (Phillips-Bute \& Lane, 1997). A step toward control for the effect of caffeine could be to analyse data while controlling for the effect of caffeine intake. Controlling for effects of confounding variables is a common practice in medical articles (Nyklíček \& Vingerhoets, 2000), and can be adopted using analysis methods such as regression.
A final matter for the experimental design is the use of dark or dimly lit rooms during the experiment. Most of the studies were not specific about the luminance level of the environment or the screen the participants were facing, but dimly lit rooms indicate low illuminance, which has been linked to low attention (Zhu et al., 2019). A recent study has attempted to disassociate mental fatigue and sleepiness $(\mathrm{Hu}$ \& Lodewijks, 2020), and while the papers in this review have attempted to control for every known factor that could induce sleep-related fatigue, performing the experiment in dimly lit rooms is a questionable practice that could be argued to cause drowsiness, either in addition to or instead of mental fatigue.

\subsection{2 | Data analysis}

Transparency in the signal processing techniques is one of the most important requirements of a paper, as it allows the experiment to be repeatable. About $40 \%$ (14 papers) of the papers included in this review did not expand on the signal processing techniques or provide a description of the metrics used. Clear signal processing techniques are especially important when the same signals are obtained using various technologies, like EEG, EOG, eye-tracking, or video cameras.

A number of the metrics used for the measurement of mental fatigue, such as PERCLOS, have been derived from sleep studies (Hu \& Lodewijks, 2020; Wierwille et al., 1994), because the concept of mental fatigue being different from sleepiness has been developed only recently in the field of psychology (Borghini et al., 2014; Hu \& Lodewijks, 2020; Lal \& Craig, 2001). There might be some basis for deriving the objective metrics from sleep studies, since both mental fatigue and drowsiness are associated with low arousal; however, it is important to determine whether the metrics respond differently to a state of mental fatigue than they do to drowsiness.

\section{5 | Future directions}

The analysis of the papers included in this review has shown that the following areas need consideration when measuring mental fatigue using eye-based features:

\subsection{1 | Studies with patients}

Multiple studies have measured mental fatigability and have found it higher in people with depression (Hopstaken et al., 2015), multiple sclerosis (Niepel et al., 2013; de Rodez Benavent et al., 2017), traumatic brain injury (Maruta et al., 2014; Möller et al., 2019), and hearing impairment (McGarrigle et al., 2017a; Wang et al., 2017) compared to 
healthy controls. Mental fatigability is a problem for these patients as a result of changing neurobiology (Chaudhuri \& Behan, 2004), and results in an expeditious feeling of mental fatigue. However, acute mental fatigue has not been studied in the patients. Understanding the progress of mental fatigue and its indicators in the target population is crucial to reducing the mental fatigability and thereby, the quality of life of the patients. Although inducing mental fatigue in patients with an underlying condition, with possible adverse effects on their health, may be ethically questionable, this can be important for the understanding and management of fatigue for the patients as well as for their caregivers.

\subsection{2 | Taking advantage of non- invasive equipment}

The non-invasive eye-tracking and EOG equipment provide a unique opportunity to assess mental fatigue in naturalistic settings, without disturbing the subject by asking questions, requesting additional tasks, or requiring the use of uncomfortable equipment. However, the use of the equipment for fatigue detection has not been brought into real-time scenarios. This is also discernible when reading the papers that used real-life scenarios of fatigue development and detection, in fields like health care (Di Stasi, McCamy, Macknik, et al., 2013), the military (Diaz-Piedra et al., 2016; LeDuc et al., 2005), or transportation (Di Stasi et al., 2016, 2012; Li, Chen et al., 2019; Wang et al., 2019). These would be the ideal situations where non-invasive, wearable equipment could continuously track the physiological signals. The current studies do not exploit the full potential of eye-tracking and EOG or their ability to detect mental fatigue using eye behavior during natural tasks.

\subsection{3 | Better understanding of mental fatigue}

The concept of mental fatigue is not standalone. It depends on sleepiness; it is affected by motivation and cognitive load, and it has an effect on attention. For a comprehensive understanding of mental fatigue, the following concepts need to be studied in relation to mental fatigue:

\section{Sleepiness}

The concepts of sleepiness and mental fatigue have only recently been differentiated in their definitions and understanding (Hu \& Lodewijks, 2020). A few metrics used for mental fatigue detection find their origin in sleep research, but it is crucial to establish whether these metrics are actually detecting mental fatigue. We have outlined a checklist on the quality of the experiment design in Table 1, which would ensure that mental fatigue is measured. We also propose controlling for confounding variables, such as caffeine intake, during data analysis.

\section{Cognitive load and motivation}

Mental fatigue is expected to be accompanied by degradation in task performance; however, that is not always the case. The reasons for this discrepancy could stem from a high motivation to maintain task performance by applying more effort despite experiencing mental fatigue. Higher cognitive load and low motivation are known to generate increased mental fatigue (Boksem et al., 2006; Borragán et al., 2017). It would be helpful to use various eye-based features in further studies on cognitive load and motivation and how they relate to mental fatigue. Another reason why performance decreases are not observed could be that mental fatigue does not exist in binary levels (i.e., fatigue/no fatigue), but ascending degrees of mental fatigue could exist, with each degree of mental fatigue affecting performance and behavior in non-linear ways.

Detection of mental fatigue in real-time can have major implications in various fields, such as critical professions like transportation, to prevent individuals from committing gross errors; like health care, to improve the quality of life of people disrupted by extreme fatigue, especially when it involves a technology used for communication, such as augmented and assisted communication system or brain-computer interfaces; and like education, to vary the length of classes depending on the topic and cognitive load it can generate. The metric that can detect mental fatigue in real-time could become a standard tool for mental health, similar to the use of heart rate to determine physical fitness.

In conclusion, the existing evidence from 34 papers shows the promise of 21 eye-based features for assessing mental fatigue. Pupil size features of baseline pupil diameter and peak pupil dilation have been shown to decrease with time-on-task; however, pupil size is currently usable in controlled laboratory settings only. The mean and peak velocity of saccades seem to have the most reliable results, even for mental activity of less than $30 \mathrm{~min}$, and are versatile in terms of environmental conditions and fatiguing tasks. The eye-based metrics found to be more sensitive to mental fatigue, than to sleepiness, were saccade peak velocity, normalized baseline pupil diameter, and EEG-derived eye movements. Blinks increase with time-on-task, indicating a decrease in arousal, but this might be an indicator of sleepiness rather than mental fatigue. This line of research requires further investigation with respect to the relationship between mental fatigue and sleepiness and the differentiation in the detection of both.

\section{CONFLICT OF INTEREST}

We have no known conflict of interest to disclose. 


\section{AUTHOR CONTRIBUTIONS}

Tanya Bafna: Conceptualization; Investigation; Methodology; Writing-original draft; Writing-review \& editing. John Paulin Hansen: Funding acquisition; Supervision; Writing-review \& editing.

\section{ORCID}

Tanya Bafna (D) https://orcid.org/0000-0002-6607-2643

John Paulin Hansen (iD https://orcid.

org/0000-0001-5594-3645

\section{REFERENCES}

Aaronson, L. S., Teel, C. S., Cassmeyer, V., Neuberger, G. B., Pallikkathayil, L., Pierce, J., Press, A. N., Williams, P. D., \& Wingate, A. (1999). Defining and measuring fatigue. Image: The Journal of Nursing Scholarship, 31(1), 45-50. https://doi. org/10.1111/j.1547-5069.1999.tb00420.x

Abbasi, A. M., Motamedzade, M., Aliabadi, M., Golmohammadi, R., \& Tapak, L. (2018). Study of the physiological and mental health effects caused by exposure to low-frequency noise in a simulated control room. Building Acoustics, 25(3), 233-248. https://doi. org/10.1177/1351010X18779518

Aston-Jones, G., \& Cohen, J. D. (2005). An integrative theory of locus coeruleus-norepinephrine function: Adaptive gain and optimal performance. Annual Review of Neuroscience, 28, 403-450. https://doi. org/10.1146/annurev.neuro.28.061604.135709

Bafna, T., \& Hansen, J. P. (2020). Mental fatigue measurement using eye-based features. Open Science Framework. http://openscienc eframework.org/project/bk93e/

Bahill, A. T., \& Stark, L. (1975). Overlapping saccades and glissades are produced by fatigue in the saccadic eye movement system. Experimental Neurology, 48(1), 95-106. https://doi. org/10.1016/0014-4886(75)90225-3

Bailey, A., Channon, S., \& Beaumont, J. G. (2007). The relationship between subjective fatigue and cognitive fatigue in advanced multiple sclerosis. Multiple Sclerosis, 13, 73-80. https://doi. org/10.1177/1352458506071162

Barz, M., Daiber, F., Sonntag, D., \& Bulling, A. (2018). Error-aware gaze-based interfaces for robust mobile gaze interaction. In Proceedings of the 2018 ACM Symposium on Eye Tracking Research and Applications, 1-10. https://doi.org/10.1145/3204493.3204536

Beurskens, A. J. H. M., Bültmann, U., Kant, I. J., Vercoulen, J. H. M. M., Bleijenberg, G., \& Swaen, G. M. H. (2000). Fatigue among working people: Validity of a questionnaire measure. Occupational and Environmental Medicine, 57(5), 353-357. https://doi.org/10.1136/ oem.57.5.353

Boksem, M. A. S., Meijman, T. F., \& Lorist, M. M. (2006). Mental fatigue, motivation and action monitoring. Biological Psychology, 72(2), 123-132. https://doi.org/10.1016/j.biopsycho.2005.08.007

Boksem, M. A. S., \& Tops, M. (2008). Mental fatigue: Costs and benefits. Brain Research Reviews, 59(1), 125-139. https://doi. org/10.1016/j.brainresrev.2008.07.001

Borghini, G., Astolfi, L., Vecchiato, G., Mattia, D., \& Babiloni, F. (2014). Measuring neurophysiological signals in aircraft pilots and car drivers for the assessment of mental workload, fatigue and drowsiness. Neuroscience and Biobehavioral Reviews, 44, 58-75. https://doi.org/10.1016/j.neubiorev.2012.10.003
Borragán, G., Gilson, M., Guerrero-Mosquera, C., Di Ricci, E., Slama, H., \& Peigneux, P. (2018). Transcranial direct current stimulation does not counteract cognitive fatigue, but induces sleepiness and an inter-hemispheric shift in brain oxygenation. Frontiers in Psychology, 9, e2351. https://doi.org/10.3389/fpsyg.2018.02351

Borragán, G., Slama, H., Bartolomei, M., \& Peigneux, P. (2017). Cognitive fatigue: A time-based resource-sharing account. Cortex, 89, 71-84. https://doi.org/10.1016/j.cortex.2017.01.023

Bryant, D., Chiaravalloti, N. D., \& DeLuca, J. (2004). Objective measurement of cognitive fatigue in multiple sclerosis. Rehabilitation Psychology, 49(2), 114-122. https://doi.org/10.1037/0090-5550.49.2.114

Burke, S. E., Samuel, I. B. H., Zhao, Q., Cagle, J., Cohen, R. A., Kluger, B., \& Ding, M. (2018). Task-based cognitive fatigability for older adults and validation of mental fatigability subscore of pittsburgh fatigability scale. Frontiers in Aging Neuroscience, 10, 1-7. https:// doi.org/10.3389/fnagi.2018.00327

Cazzoli, D., Antoniades, C. A., Kennard, C., Nyffeler, T., Bassetti, C. L., \& Müri, R. M. (2014). Eye movements discriminate fatigue due to chronotypical factors and time spent on task-A double dissociation. PLoS One, 9(1), e87146. https://doi.org/10.1371/journ al.pone.0087146

Chalder, T., Berelowitz, G., Pawlikowska, T., Watts, L., Wessely, S., Wright, D., \& Wallace, E. P. (1993). Development of a fatigue scale. Journal of Psychosomatic Research, 37(2), 147-153. https://doi. org/10.1016/0022-3999(93)90081-P

Chaudhuri, A., \& Behan, P. O. (2004). Fatigue in neurological disorders. The Lancet, 363, 978-988. https://doi.org/10.1016/S0140 $-6736(04) 15794-2$

Connell, C. J. W., Thompson, B., Turuwhenua, J., Hess, R. F., \& Gant, N. (2017). Caffeine increases the velocity of rapid eye movements in unfatigued humans. Psychopharmacology (Berl), 234(15), 23112323. https://doi.org/10.1007/s00213-017-4638-1

Dawson, D., Searle, A. K., \& Paterson, J. L. (2014). Look before you (s)leep: Evaluating the use of fatigue detection technologies within a fatigue risk management system for the road transport industry. Sleep Medicine Reviews, 18(2), 141-152. https://doi.org/10.1016/j. smrv.2013.03.003

de Rodez Benavent, S. A., Nygaard, G. O., Harbo, H. F., Tønnesen, S., Sowa, P., Landrø, N. I., Wendel-Haga, M., Etholm, L., Nilsen, K. B., Drolsum, L., Kerty, E., Celius, E. G., \& Laeng, B. (2017). Fatigue and cognition: Pupillary responses to problem-solving in early multiple sclerosis patients. Brain and Behavior, 7(7), 1-12. https://doi. org/10.1002/brb3.717

Di Stasi, L. L., McCamy, M. B., Catena, A., Macknik, S. L., Cañas, J. J., \& Martinez-Conde, S. (2013). Microsaccade and drift dynamics reflect mental fatigue. European Journal of Neuroscience, 38(3), 2389-2398. https://doi.org/10.1111/ejn.12248

Di Stasi, L. L., McCamy, M. B., Macknik, S. L., Mankin, J. A., Hooft, N., Catena, A., \& Martinez-Conde, S. (2013). Saccadic eye movement metrics reflect surgical residents' fatigue. Annals of Surgery, 259(4), 824-829. https://doi.org/10.1097/SLA.00000 00000000260

Di Stasi, L. L., McCamy, M. B., Martinez-Conde, S., Gayles, E., Hoare, C., Foster, M., Catena, A., \& Macknik, S. L. (2016). Effects of long and short simulated flights on the saccadic eye movement velocity of aviators. Physiology and Behavior, 153, 91-96. https://doi. org/10.1016/j.physbeh.2015.10.024

Di Stasi, L. L., McCamy, M. B., Pannasch, S., Renner, R., Catena, A., Cañas, J. J., Velichkovsky, B. M., \& Martinez-Conde, S. (2015). 
Effects of driving time on microsaccadic dynamics. Experimental Brain Research, 233(2), 599-605. https://doi.org/10.1007/s0022 1-014-4139-y

Di Stasi, L. L., Renner, R., Catena, A., Cañas, J. J., Velichkovsky, B. M., \& Pannasch, S. (2012). Towards a driver fatigue test based on the saccadic main sequence: A partial validation by subjective report data. Transportation Research Part C: Emerging Technologies, 21(1), 122-133. https://doi.org/10.1016/j.trc.2011.07.002

Diaz-Piedra, C., Rieiro, H. H., Suarez, J., Rios-Tejada, F., Suárez, J., Rios-Tejada, F., Catena, A., \& Di Stasi, L. L. (2016). Fatigue in the military: Towards a fatigue detection test based on the saccadic velocity. Physiological Measurement, 37(9), 62-75. https://doi. org/10.1088/0967-3334/37/9/N62

Dinges, D. F., \& Kribbs, N. B. (1991). Performing while sleepy: Effects of experimentally-induced sleepiness. In T. H. Monk (Ed.), Sleep, sleepiness and performance (pp. 97-128). John Wiley \& Sons.

Eckstein, M. K., Guerra-Carrillo, B., Miller Singley, A. T., \& Bunge, S. A. (2017). Beyond eye gaze: What else can eyetracking reveal about cognition and cognitive development? Developmental Cognitive Neuroscience, 25, 69-91. https://doi.org/10.1016/j.dcn.2016.11.001

Eldadah, B. A. (2010). Fatigue and fatigability in older adults. American Academy of Physical Medicine and Rehabilitation, 2(5), 406-413. https://doi.org/10.1016/j.pmrj.2010.03.022

Eriksen, B. A., \& Eriksen, C. W. (1974). Effects of noise letters upon the identification of a target letter in a nonsearch task. Perception \& Psychophysics, 16(1), 143-149. https://doi.org/10.3758/BF032 03267

Fan, J., McCandliss, B. D., Sommer, T., Raz, A., \& Posner, M. I. (2002). Testing the efficiency and independence of attentional networks. Journal of Cognitive Neuroscience, 14(3), 340-347. https://doi. org/10.1162/089892902317361886

Finke, C., Pech, L. M., Sömmer, C., Schlichting, J., Stricker, S., Endres, M., Ostendorf, F., Ploner, C. J., Brandt, A. U., \& Paul, F. (2012). Dynamics of saccade parameters in multiple sclerosis patients with fatigue. Journal of Neurology, 259(12), 2656-2663. https://doi. org/10.1007/s00415-012-6565-8

Finsterer, J., \& Mahjoub, S. Z. (2014). Fatigue in healthy and diseased individuals. American Journal of Hospice and Palliative Medicine, 31(5), 562-575. https://doi.org/10.1177/1049909113494748

Fisk, J. D., Ritvo, P. G., Ross, L., Haase, D. A., Marrie, T. J., \& Schlech, W. F. (1994). Measuring the functional impact of fatigue: Initial validation of the fatigue impact scale. Clinical Infectional Diseases, 18(Supplement_1), 79-83. https://doi.org/10.1093/clinids/18.Suppl ement_1.S79

Gao, X.-Y., Zhang, Y.-F., Zheng, W.-L., \& Lu, B.-L. (2015). Evaluating driving fatigue detection algorithms using eye tracking glasses. In 7th International IEEE/EMBS Conference on Neural Engineering, (July 2015), 767-770. https://doi.org/10.1109/NER.2015.7146736

Gergelyfi, M., Jacob, B., Olivier, E., \& Zénon, A. (2015). Dissociation between mental fatigue and motivational state during prolonged mental activity. Frontiers in Behavioral Neuroscience, 9, 176. https://doi.org/10.3389/fnbeh.2015.00176

Gibbons, C. J., Thornton, E. W., \& Young, C. A. (2013). The patient experience of fatigue in motor neurone disease. Frontiers in Psychology, 4, 1-9. https://doi.org/10.3389/fpsyg.2013.00788

Guo, Z., Chen, R., Liu, X., Zhao, G., Zheng, Y., Gong, M., \& Zhang, J. (2018). The impairing effects of mental fatigue on response inhibition: An ERP study. PLoS One, 13(6), e0198206. https://doi. org/10.1371/journal.pone.0198206
Herlambang, M. B., Taatgen, N. A., \& Cnossen, F. (2019). The role of motivation as a factor in mental fatigue. Human Factors, 61(7), 1171-1185. https://doi.org/10.1177/0018720819828569

Hirvonen, K., Puttonen, S., Gould, K., Korpela, J., Koefoed, V. F., \& Müller, K. (2010). Improving the saccade peak velocity measurement for detecting fatigue. Journal of Neuroscience Methods, 187(2), 199-206. https://doi.org/10.1016/j.jneumeth.2010.01.010

Hopstaken, J. F., van der Linden, D., Bakker, A. B., \& Kompier, M. A. J. (2015a). A multifaceted investigation of the link between mental fatigue and task disengagement. Psychophysiology, 52(3), 305-315. https://doi.org/10.1111/psyp.12339

Hopstaken, J. F., van der Linden, D., Bakker, A. B., \& Kompier, M. A. J. (2015b). The window of my eyes: Task disengagement and mental fatigue covary with pupil dynamics. Biological Psychology, 110, 100-106. https://doi.org/10.1016/j.biopsycho.2015.06.013

Hopstaken, J. F., van der Linden, D., Bakker, A. B., Kompier, M. A. J., \& Leung, Y. K. (2016). Shifts in attention during mental fatigue: Evidence from subjective, behavioral, physiological, and eye-tracking data. Journal of Experimental Psychology: Human Perception and Performance, 42(6), 878-889. https://doi.org/10.1037/xhp0000189

Hopstaken, J. F., Wanmaker, S., van der Linden, D., \& Bakker, A. B. (2015). Does dysphoria lead to divergent mental fatigue effects on a cognitive task? PLoS One, 10(6), e0130304. https://doi.org/10.1371/ journal.pone.0130304

Horiuchi, R., Ogasawara, T., \& Miki, N. (2018). Fatigue assessment by blink detected with attachable optical sensors of dye-sensitized photovoltaic cells. Micromachines, 9(6), 310. https://doi.org/10.3390/ mi9060310

Hu, X., \& Lodewijks, G. (2020). Detecting fatigue in car drivers and aircraft pilots by using non-invasive measures: The value of differentiation of sleepiness and mental fatigue. Journal of Safety Research, 72, 173-187. https://doi.org/10.1016/j.jsr.2019.12.015

Itoh, K., Tanaka, H., \& Seki, M. (2000). Eye-movement analysis of track monitoring patterns of night train operators: Effects of geographic knowledge and fatigue. Proceedings of the Human Factors and Ergonomics Society Annual Meeting, 44(27), 360-363. https://doi. org/10.1177/154193120004402721

Johansson, B., Starmark, A., Berglund, P., Rödholm, M., \& Rönnbäck, L. (2010). A self-assessment questionnaire for mental fatigue and related symptoms after neurological disorders and injuries. Brain Injury, 24(1), 2-12. https://doi.org/10.3109/02699050903452961

Jongkees, B. J., \& Colzato, L. S. (2016). Spontaneous eye blink rate as predictor of dopamine-related cognitive function-A review. Neuroscience and Biobehavioral Reviews, 71, 58-82. https://doi. org/10.1016/j.neubiorev.2016.08.020

Kluger, B. M., Krupp, L. B., \& Enoka, R. M. (2013). Fatigue and fatigability in neurologic illnesses: Proposal for a unified taxonomy. Neurology, 80(4), 409-416. https://doi.org/10.1212/WNL.0b013 e31827f07be

Kramer, A. F. (1991). Physiological metrics of mental workload: A review of recent progress. In D. L. Damos (Ed.), Multiple task performance (pp. 279-328). Taylor and Francis. https://doi. org/10.1080/00140139.2014.956151

Lal, S. K. L., \& Craig, A. (2001). A critical review of the psychophysiology of driver fatigue. Biological Psychology, 55(3), 173-194. https://doi.org/10.1016/S0301-0511(00)00085-5

Lavine, R. A., Sibert, J. L., Gokturk, M., \& Dickens, B. (2002). Eyetracking measures and human performance in a vigilance task. Aviation Space and Environmental Medicine, 73(4), 367-372. 
LeDuc, P. A., Greig, J. L., \& Dumond, S. L. (2005). Involuntary eye responses as measures of fatigue in U.S. Army Apache aviators. Aviation, Space, and Environmental Medicine, 76(7 II), C86-C91.

Li, F., Chen, C.-H., Xu, G., Khoo, L. P., \& Liu, Y. (2019). Proactive mental fatigue detection of traffic control operators using bagged trees and gaze-bin analysis. Advanced Engineering Informatics, 42, 100987. https://doi.org/10.1016/j.aei.2019.100987

Li, J., Li, H., Wang, H., Umer, W., Fu, H., \& Xing, X. (2019). Evaluating the impact of mental fatigue on construction equipment operators' ability to detect hazards using wearable eye-tracking technology. Automation in Construction, 105, 102835. https://doi.org/10.1016/j. autcon.2019.102835

Linnhoff, S., Fiene, M., Heinze, H. J., \& Zaehle, T. (2019). Cognitive fatigue in multiple sclerosis: An objective approach to diagnosis and treatment by transcranial electrical stimulation. Brain Sciences, 9(5), 1-23. https://doi.org/10.3390/brainsci9050100

Lou, J.-S. (2009). Physical and mental fatigue in Parkinson's disease. Drugs \& Aging, 26(3), 195-208. https://doi.org/10.2165/00002512200926030-00002

Maffei, A., \& Angrilli, A. (2018). Spontaneous eye blink rate: An index of dopaminergic component of sustained attention and fatigue. International Journal of Psychophysiology, 123, 58-63. https://doi. org/10.1016/j.ijpsycho.2017.11.009

Mairesse, O., Damen, V., Newell, J., Kornreich, C., Verbanck, P., \& Neu, D. (2017). The brugmann fatigue scale: An analogue to the epworth sleepiness scale to measure behavioral rest propensity. Behavioral Sleep Medicine, 17(4), 437-458. https://doi.org/10.1080/15402 002.2017.1395336

Marandi, R. Z., Madeleine, P., Omland, O., Vuillerme, N., \& Samani, A. (2018). Eye movement characteristics reflected fatigue development in both young and elderly individuals. Scientific Reports, 8(1), 1-10. https://doi.org/10.1038/s41598-018-31577-1

Marandi, R. Z., Madeleine, P., Omland, Ø., Vuillerme, N., \& Samani, A. (2019). An oculometrics-based biofeedback system to impede fatigue development during computer work: A proof-of-concept study. PLoS One, 14(5), e0213704. https://doi.org/10.1371/journ al.pone.0213704

Martins, R., \& Carvalho, J. (2015). Eye blinking as an indicator of fatigue and mental load-A systematic review. Occupational Safety and Hygiene III, 10, 231-235. https://doi.org/10.1201/b18042-48

Maruta, J., Heaton, K. J., Maule, A. L., \& Ghajar, J. (2014). Predictive visual tracking: Specificity in mild traumatic brain injury and sleep deprivation. Military Medicine, 179(6), 619-625. https://doi. org/10.7205/MILMED-D-13-00420

May, J. F., \& Baldwin, C. L. (2009). Driver fatigue: The importance of identifying causal factors of fatigue when considering detection and countermeasure technologies. Transportation Research Part F: Traffic Psychology and Behaviour, 12(3), 218-224. https://doi. org/10.1016/j.trf.2008.11.005

McGarrigle, R., Dawes, P., Stewart, A. J., Kuchinsky, S. E., \& Munro, K. J. (2017a). Pupillometry reveals changes in physiological arousal during a sustained listening task. Psychophysiology, 54(2), 193203. https://doi.org/10.1111/psyp.12772

McGarrigle, R., Dawes, P., Stewart, A. J., Kuchinsky, S. E., \& Munro, K. J. (2017b). Measuring listening-related effort and fatigue in schoolaged children using pupillometry. Journal of Experimental Child Psychology, 161, 95-112. https://doi.org/10.1016/j.jecp.2017.04.006

Meijman, T. F. (1997). Mental fatigue and the efficiency of information processing in relation to work times. International Journal of
Industrial Ergonomics, 20(1), 31-38. https://doi.org/10.1016/S0169 -8141(96)00029-7

Mills, R. J., \& Young, C. A. (2008). A medical definition of fatigue in multiple sclerosis. QJM: An International Journal of Medicine, 101(1), 49-60. https://doi.org/10.1093/qjmed/hcm122

Miura, K., \& Optican, L. M. (2006). Membrane channel properties of premotor excitatory burst neurons may underlie saccade slowing after lesions of omnipause neurons. Journal of Computational Neuroscience, 20(1), 25-41. https://doi.org/10.1007/s1082 7-006-4258-y

Moher, D., Liberati, A., Tetzlaff, J., \& Altman, D. G., \& The PRISMA Group. (2009). Preferred reporting items for systematic reviews and meta-analyses: The PRISMA statement. PLoS Med, 6(7), e1000097. https://doi.org/10.1371/journal.pmed.1000097

Möller, M., Johansson, J., Matuseviciene, G., Pansell, T., \& Deboussard, C. N. (2019). An observational study of trait and state fatigue, and their relation to cognitive fatigability and saccade performance. Concussion, 4(2), CNC62. https://doi.org/10.2217/cnc-2019-0003

Monteiro, T. G., Skourup, C., \& Zhang, H. (2019). Using EEG for mental fatigue assessment: A comprehensive look into the current state of the art. IEEE Transactions on Human-Machine Systems, 49(6), 599-610. https://doi.org/10.1109/THMS.2019.2938156

Morad, Y., Lemberg, H., Yofe, N., \& Dagan, Y. (2000). Pupillography as an objective indicator of fatigue. Current Eye Research, 21(1), 535542. https://doi.org/10.1076/0271-3683(200007)21:1;1-z;ft535

Neu, D., Mairesse, O., Hoffmann, G., Valsamis, J. B., Verbanck, P., Linkowski, P., \& Le Bon, O. (2010). Do "sleepy" and "tired" go together? Rasch analysis of the relationships between sleepiness, fatigue and nonrestorative sleep complaints in a nonclinical population sample. Neuroepidemiology, 35(1), 1-11. https://doi. org/10.1159/000301714

Nielsen, H. B., Hansen, Å. M., Conway, S. H., Dyreborg, J., Hansen, J., Kolstad, H. A., Larsen, A. D., Nabe-Nielsen, K., Pompeii, L. A., \& Garde, A. H. (2019). Short time between shifts and risk of injury among Danish hospital workers: A register-based cohort study. Scandinavian Journal of Work, Environment and Health, 45(2), 166-173. https://doi.org/10.5271/sjweh.3770

Nieoullon, A. (2002). Dopamine and the regulation of cognition and attention. Progress in Neurobiology, 67(1), 53-83. https://doi. org/10.1016/S0301-0082(02)00011-4

Niepel, G., Bibani, R. H., Vilisaar, J., Langley, R. W., Bradshaw, C. M., Szabadi, E., \& Constantinescu, C. S. (2013). Association of a deficit of arousal with fatigue in multiple sclerosis: Effect of modafinil. Neuropharmacology, 64, 380-388. https://doi.org/10.1016/j.neuro pharm.2012.06.036

Nyklíček, I., \& Vingerhoets, A. J. J. M. (2000). Alexithymia is associated with low tolerance to experimental painful stimulation. Pain, 85(3), 471-475. https://doi.org/10.1016/S0304-3959(99)00295-X

Optican, L. M. (2008). The role of omnipause neurons: Why glycine? Progress in Brain Research, 171(08), 115-121. https://doi. org/10.1016/S0079-6123(08)00615-8

Paladini, R. E., Diana, L., Nyffeler, T., Mosimann, U. P., Nef, T., Müri, R. M., \& Cazzoli, D. (2016). The asymmetrical influence of increasing time-on-task on attentional disengagement. Neuropsychologia, 92, 107-114. https://doi.org/10.1016/j.neuropsychologia.2016.02.026

Pattyn, N., Neyt, X., Henderickx, D., \& Soetens, E. (2008). Psychophysiological investigation of vigilance decrement: Boredom or cognitive fatigue? Physiology and Behavior, 93(1-2), 369-378. https://doi.org/10.1016/j.physbeh.2007.09.016 
Pattyn, N., Van Cutsem, J., Dessy, E., \& Mairesse, O. (2018). Bridging exercise science, cognitive psychology, and medical practice: Is "Cognitive Fatigue" a remake of "The Emperor's New Clothes"? Frontiers in Psychology, 9. https://doi.org/10.3389/fpsyg.2018.01246

Phillips, R. O. (2015). A review of definitions of fatigue-And a step towards a whole definition. Transportation Research Part F: Traffic Psychology and Behaviour, 29, 48-56. https://doi.org/10.1016/j. trf.2015.01.003

Phillips-Bute, B. G., \& Lane, J. D. (1997). Caffeine withdrawal symptoms following brief caffeine deprivation. Physiology and Behavior, 63(1), 35-39. https://doi.org/10.1016/S0031-9384(97)00384-3

Piper, B. F., Dibble, S. L., Dodd, M. J., Weiss, M. C., Slaughter, R. E., $\&$ Paul, S. M. (1998). The revised piper fatigue scale: Psychometric evaluation in women with breast cancer. Oncology Nursing Forum, 25(4), 677-684.

Portman-Tiller, C. A. (1998). The fitness impairment test (FIT): A first look. Report No. NAMRL-1401. Naval Medical Research Laboratory. https://apps.dtic.mil/dtic/tr/fulltext/u2/a350435.pdf

Purves, D., Augustine, G. J., Fitzpatrick, D., Katz, L. C., LaMantia, A.-S., McNamara, J. O., \& Williams, S. M. (2001). Neural control of saccadic eye movements. In Neuroscience, 2nd ed. Sinauer Associates. https://www.ncbi.nlm.nih.gov/books/NBK10992/

Ream, E., \& Richardson, A. (1996). Fatigue: A concept analysis. International Journal of Nursing Studies, 33(5), 519-529. https:// doi.org/10.1016/0020-7489(96)00004-1

Renata, V., Li, F., Lee, C.-H., \& Chen, C.-H. (2018). Investigation on the correlation between eye movement and reaction time under mental fatigue influence. (pp. 207-213). In 2018 International Conference on Cyberworlds. https://doi.org/10.1109/CW.2018.00046

Ricci, J. A., Chee, E., Lorandeau, A. L., \& Berger, J. (2007). Fatigue in the U.S. workforce: Prevalence and implications for lost productive work time. Journal of Occupational and Environmental Medicine, 49(1), 1-10. https://doi.org/10.1097/01.jom.0000249782.60321.2a

Richter, M., Gendolla, G. H. E., \& Wright, R. A. (2016). Three decades of research on motivational intensity theory. In A. J. Elliot (Ed.) Advances in motivation science (Vol. 3, pp. 149-186). Elsevier. https://doi.org/10.1016/bs.adms.2016.02.001

Schlosser, K., Maschuw, K., Kupietz, E., Weyers, P., Schneider, R., Rothmund, M., Hassan, I., \& Bartsch, D. K. (2012). Call-associated acute fatigue in surgical residents-subjective perception or objective fact? A cross-sectional observational study to examine the influence of fatigue on surgical performance. World Journal of Surgery, 36(10), 2276-2287. https://doi.org/10.1007/s00268-012-1699-5

Schmidt, L. A., Abel, L. A., Dell'Osso, L. F., \& Daroff, R. B. (1979). Saccadic velocity characteristics: Intrinsic variability and fatigue. Aviation, Space, and Environmental Medicine, 46, 393-395. http:// omlab.org/Personnel/lfd/Jrnl_Arts/033_Sacc_Vel_Chars_Intrinsic_ Variability_Fatigue_1979.pdf

Sengupta, A., Dasgupta, A., Chaudhuri, A., George, A., Routray, A., \& Guha, R. (2017). A multimodal system for assessing alertness levels due to cognitive loading. IEEE Transactions on Neural Systems and Rehabilitation Engineering, 25(7), 1037-1046. https://doi. org/10.1109/TNSRE.2017.2672080

Shen, J., Barbera, J., \& Shapiro, C. M. (2006). Distinguishing sleepiness and fatigue: Focus on definition and measurement. Sleep Medicine Reviews, 10(1), 63-76. https://doi.org/10.1016/j.smrv.2005.05.004

Shen, K. Q., Li, X. P., Ong, C. J., Shao, S. Y., \& Wilder-Smith, E. P. V. (2008). EEG-based mental fatigue measurement using multi-class support vector machines with confidence estimate. Clinical Neurophysiology, 119(7), 1524-1533. https://doi.org/10.1016/j.clinph.2008.03.012
Smets, E. M. A., Garssen, B., Bonke, B., \& De Haes, J. C. J. M. (1995). The multidimensional fatigue inventory (MFI) psychometric qualities of an instrument to assess fatigue. Journal of Psychosomatic Research, 39(5), 315-325. https://doi.org/10.1016/0022-3999(94)00125-O

Song, J., Xiong, C., Wang, R., Zhang, L., Zhang, G., \& Sun, C. (2015). Electrooculogram signals analysis for process control operator based on fuzzy c-means. International Journal of Advanced Computer Science and Applications, 6(9), 138-142. https://doi.org/10.14569/ IJACSA.2015.060918

Stern, J. A., Walrath, L. C., \& Goldstein, R. (1984). The endogenous eyeblink. Psychophysiology, 21(1), 22-33. https://doi.org/10.1111/ j.1469-8986.1984.tb02312.x

Tag, B., Vargo, A. W., Gupta, A., Chernyshov, G., Kunze, K., \& Dingler, T. (2019). Continuous alertness assessments: Using EOG glasses to unobtrusively monitor fatigue levels in-the-wild. In Proceedings of the 2019 CHI Conference on Human Factors in Computing Systems, 1-12. https://doi.org/10.1145/3290605.3300694

Tanaka, M., Ishii, A., \& Watanabe, Y. (2014). Neural effects of mental fatigue caused by continuous attention load: A magnetoencephalography study. Brain Research, 1561, 60-66. https://doi.org/10.1016/j. brainres.2014.03.009

Tian, Y., Chen, S., Wang, C., Yan, Q., \& Wang, Z. (2012). Investigations on eye movement activities in the manually controlled rendezvous and docking of space vehicles. In T. Z. Ahram, \& K. Waldemar (Eds.), Advances in Physical Ergonomics and Safety (pp. 182-189). CRC Press.

Tran, Y., Craig, A., Craig, R., Chai, R., \& Nguyen, H. (2020). The influence of mental fatigue on brain activity: Evidence from a systematic review with meta-analyses. Psychophysiology, 57, e13554. https:// doi.org/10.1111/psyp.13554

van der Linden, D. (2011). The urge to stop: The cognitive and biological nature of acute mental fatigue. In P. L. Ackerman (Ed.), Cognitive fatigue: Multidisciplinary perspectives on current research and future applications (pp. 149-164). American Psychological Association. https://doi.org/10.1037/12343-007

Wang, F., Xu, Q., \& Fu, R. (2019). Study on the effect of man-machine response mode to relieve driving fatigue based on EEG and EOG. Sensors, 19(22), 4883. https://doi.org/10.3390/s19224883

Wang, Y., Naylor, G., Kramer, S. E., Zekveld, A. A., Wendt, D., Ohlenforst, B., \& Lunner, T. (2017). Relations between self-reported daily-life fatigue, hearing status, and pupil dilation during a speech perception in noise task. Ear and Hearing, 39(3), 573-582. https:// doi.org/10.1097/AUD.0000000000000512

Wei, Q., Lee, J. H., \& Park, H.-J. (2019). Novel design of smart sleeplighting system for improving the sleep environment of children. Technology and Health Care, 27(S1), 3-13. https://doi.org/10.3233/ THC-199002

Whitehead, L. (2009). The measurement of fatigue in chronic illness: A systematic review of unidimensional and multidimensional fatigue measures. Journal of Pain and Symptom Management, 37(1), 107128. https://doi.org/10.1016/j.jpainsymman.2007.08.019

Wierwille, W. W., Ellsworth, L. A., Wreggit, S. S., Fairbanks, R. J., \& Kirn, C. L. (1994). Research on vehicle-based driver status/performance monitoring; development, validation, and refinement of algorithms for detection of driver drowsiness (Report no. DOT HS 808 247). : National Highway Traffic Safety Administration. https:// doi.org/10.1037/e526682009-001

Wise, J. M., Heaton, K., \& Patrician, P. (2019). Fatigue in long-haul truck drivers: A concept analysis. Workplace Health \& Safety, 67(2), 68-77. https://doi.org/10.1177/2165079918800509 
Yamada, Y., \& Kobayashi, M. (2018). Detecting mental fatigue from eye-tracking data gathered while watching video: Evaluation in younger and older adults. Artificial Intelligence in Medicine, 91, 39-48. https://doi.org/10.1016/j.artmed.2018.06.005

Zhu, Y., Yang, M., Yao, Y., Xiong, X., Li, X., Zhou, G., \& Ma, N. (2019). Effects of illuminance and correlated color temperature on daytime cognitive performance, subjective mood, and alertness in healthy adults. Environment and Behavior, 51(2), 199-230. https:// doi.org/10.1177/0013916517738077

Zijdewind, I., Prak, R. F., \& Wolkorte, R. (2016). Fatigue and fatigability in persons with multiple sclerosis. Exercise and Sport Sciences Reviews, 44(4), 123-128. https://doi.org/10.1249/JES.0000000000000088
SUPPORTING INFORMATION

Additional supporting information may be found online in the Supporting Information section.

How to cite this article: Bafna T, Hansen JP. Mental fatigue measurement using eye metrics: A systematic literature review. Psychophysiology. 2021;00:e13828. https://doi.org/10.1111/psyp.13828 